\title{
Pawet Urbanik*
}

\section{Getting others to share goods in Polish and Norwegian: Material and moral anchors for request conventions}

\author{
https://doi.org/10.1515/ip-2020-0009
}

\begin{abstract}
The paper examines the formation of requests for sharing goods in Polish and Norwegian by focusing on the use of imperatives and Can I-interrogatives in informal settings. The study first identifies the contextual, material and embodied configurations that contribute to the selection of constructions. Then, it explores the moral roots of the divergent use of formats in similar configurations across the two languages. Employing a multimodal interactional-linguistic approach to comparable conversational data from Polish and Norwegian reality show corpora, the study demonstrates that the selection of format relies on the object's control status and the requester's orientation to contingencies. Imperatives are selected when the object is controlled by the requestee and no contingencies are recognized. Can I-interrogatives mark orientation to contingencies and have two realization patterns: Depending on whether the object is controlled by the requestee or not, they are used as transfer or permission requests, respectively. The study also reveals cultural differences in the selection of imperatives and transfer interrogatives across the languages. The Polish participants most often treated sharing as the requestee's social obligation, using imperatives in the environments in which their Norwegian counterparts chose transfer interrogatives and marked that the requestee's readiness to share was not taken for granted.
\end{abstract}

Keywords: Polish, Norwegian, requests, imperatives, interrogatives, sharing goods, action formation

\section{Introduction}

Our daily request practices concern various responsive actions we expect others will do for us. One of such actions is to share things. As opposed to fetching or passing objects, where the requestee merely mediates between the object and the requester, sharing is oriented to in terms of relocation of the requestee's ownership rights to

*Corresponding author: Pawet Urbanik, University of Oslo, Oslo, Norway, E-mail: p.k.urbanik@iln.uio.no 
the requester. Requests for sharing can be realized in various ways: We may, for instance, ask or tell the other to transfer the object s/he is holding to us or we may ask whether we can use the object that belongs to him/her.

Previous research on requests has not focused specifically on sharing as a distinct responsive action. However, a recent study on requesting practices in Polish and Norwegian (Urbanik 2017) has indicated that this event can be consequential for the grammatical formation of requests and cross-cultural differences in this respect. The present study draws on those observations and investigates the contextual conditions of requests for sharing in detail, taking into account not only grammatical formats, but also material and embodied means that co-participate in the action formation and recognition.

The paper focuses on the use of two most standard and common formats selected as requests for sharing in the Polish and the Norwegian data: imperatives and Can I-interrogatives. By employing a multimodal interactional-linguistic approach, it explores the sequential environments in which these constructions are used and identifies the material and embodied configurations that accompany the formats and co-constitute the actions performed. Thus, the main goal of the study is to explore in what conditions the speakers of the two languages build their requests for sharing in one syntactic way or another. This is to find out what makes requests for sharing recognizable social actions in Polish and Norwegian, but also to what extent these languages follow similar mechanisms of action formation and where they differ.

Recent conversation-analytic research has demonstrated that the significance of cross-cultural differences in interaction can be systematically traced by a detailed analysis of participants' local orientations (Sidnell and Enfield 2012; Zinken and Ogiermann 2013). Therefore, the second aim of this study is to explore what deeper roots of cross-cultural differences can be found in the participants' local selection of specific grammatical formats. This is done through comparison of similar environments in which the Polish and the Norwegian participants use divergent conventions.

\section{Sharing and requesting}

Sharing has been claimed to be a fundamental human trait (Moravcsik 2004) and one of the main displays of human altruism and cooperation manifested already in early childhood (Hay and Cook 2007; Warneken and Tomasello 2009a; Schmidt and Sommerville 2011). Particularly humans' willingness to share food with others (including non-relatives) is often seen as a special case of cooperative and altruistic 
social behavior, absent or extremely rare among non-human primates (Kaplan and Hill 1985; Gurven 2004; Tomasello 2009; Warneken and Tomasello 2009a; Gurven and Jaeggi 2015; Silk and House 2016). It has been observed that willingness to share is manifested before culture properly comes into play, as children become generous with food and other resources already during the second year of life (Hay 1979; Hay and Cook 2007; Brownell et al. 2009; Warneken and Tomasello 2009a; Schmidt and Sommerville 2011; Brownell et al. 2013). Yet, the development of prosocial behavior, although probably based on altruistic predisposition, is significantly steered by moral and conventional norms (Fehr et al. 2008; Warneken and Tomasello 2009a, Warneken and Tomasello 2009b; Takada and Endo 2015). Some researchers emphasize that what often motivates sharing are verbal and nonverbal signals about the recipient's needs and desires (Hay and Cook 2007; Brownell et al. 2009; Rossano and Liebal 2014). It has been noted that requesting (together with the absence of food) triggers altruistic reactions among primates, and "recipient-initiated" cooperation may therefore elucidate how altruism has evolved in humans and become unique to them in the situations in which requesting does not occur (Yamamoto and Tanaka 2009; cf. Warneken and Tomasello 2006; Rossano and Liebal 2014). This indicates that sharing is an action that seems to be deeply rooted in the organization of humans' social life and its link to language goes through requesting. It has even been claimed that requesting implementing speaker-initiated sharing (as opposed to offering that implements recipient-initiated sharing) is a primordial type of actions in human evolution (Rossano and Liebal 2014).

Yet, contrary to psychology, very little attention has been paid to sharing in linguistics and pragmatics. Studies on social actions or speech acts that involve sharing, such as requests, have not systematically explored it as an event to which language users might orient and adjust their linguistic means. Several researchers have mentioned the role of such conditions as ownership in request formation (a parameter investigated in this study) but without directly linking it to sharing events (Gordon and Ervin-Tripp 1984; Ervin-Tripp and Gordon 1986; Dixon 2015). Moreover, requests, especially in cross-linguistic comparisons, have mostly been treated as container actions that simply serve to "get others to do X" (cf. Searle 1969). Although they have been broadly studied for over 50 years now, only recently have researchers become more interested in the specificity of the work requests do in interaction and in the sequential conditions of their grammatical formations (but see Wootton 1981, Wootton 1997). Studies in conversation analysis have shown that the details of lexicosyntactic composition and local use are consequential for the accountability of action. The above mentioned X-element can be crucial for the position and the function of a certain request format (Fox and Heinemann 2016, 2017) and requests, except for getting others to do things, can do much more at a given point of interaction (e. g. mark 
different stances), although perhaps "less officially" (Levinson 2013). This is particularly crucial for the present study that narrows the analysis to a particular type of requests and investigates how participants orient to the event these requests create. In interactional terms, requesting and sharing examined here compose a sequence organizational unit, a type of an adjacency pair (Schegloff 2007), where sharing (compliance performed physically or verbally, or both) is the preferred responsive action to requesting indicating what is to be shared.

\section{Requests for objects: Grammar, materiality, and agency}

The conversation-analytic turn in the field has challenged some of the previous claims about requesting practices and provided new insights into their characteristics (see e. g. Drew and Couper-Kuhlen 2014a; Sorjonen et al. 2017). Researchers have noted that among the conditions that may affect the selection of request formats is whether the requested action concerns an object and aims at, for instance, passing or fetching it, or whether it concerns people and their services such as coming closer or making a cup of coffee (Drew and Couper-Kuhlen 2014b; cf. Urbanik 2017). Recent studies on object requests targeting an immediate action in everyday informal interactions have mainly focused on two issues: 1) the employment of certain grammatical formats doing the work of object requests, and 2) the role of objects in the sequential unfolding of interaction and the emergence of request formats.

In the former cases, object requests, as a subclass of requests in general, serve as points of departure for the identification of specific local conditions that go hand in hand with particular grammatical formats. Rossi $(2012,2015)$ shows that grammatical designs of requests involving the transfer of an object follow particular configurational patterns. Both imperatives and plain interrogatives (i. e. non-modal forms) in Italian are selected when objects belong to shared goods available at the moment of requesting. Yet, the former are embedded in the projects to which the speaker and the recipient are already committed, while the latter initiate new, individually owned, projects (Rossi 2012). Zinken and Ogiermann (2013) confirm these observations, demonstrating that in English and Polish imperatives serve joint actions by referring to the recipient's co-responsibility, while Can you-formats introduce new actions that require the recipients to departure from their own activities. On the other hand, Do you have-interrogatives, as observed in Italian, mark the speakers' orientations to object ownership and availability (Rossi 2015). These, among other formats, are also analyzed by Ogiermann (2015) who focuses on requests formulated as hints in Polish family interactions. She notes that such constructions are usually 
treated as routine forms embedded in rich material environments that make them fully transparent.

In the latter group of studies particular attention has been paid to the objects themselves and the conditions their local use co-constitutes for the selection of certain grammatical formats. The significance of material and embodied environments is observed in early phases of child development, and adult-child interactions rely on multimodal contexts (cf. Bruner et al. 1982). Takada and Endo (2015), who have studied how Japanese caregivers request children to transfer objects, emphasize that features such as the object's accessibility (its placement) and ownership are relevant for the caregivers to assess the probability of compliance with the request. The issue of ownership is elaborated by Dixon (2015) who has examined a group of Australian Aboriginal children playing with objects. She demonstrates that the selection of an imperative request accompanied by grabbing the thing is built upon the speaker's ownership claims and reveals the current configuration of the claimed rights and their reasons. Zinken (2015) demonstrates, in turn, how a grammatical design of requests marks orientation to artifacts and their spatial arrangements. One of the possible uses of the English Can I have-format is to ask for transferring an object that is currently controlled by the recipient. Zinken claim is that precisely this "contingent control" over the requested object is what the format indexes, positing a sense of obligation on the part of the recipient for transferring the object in the contexts in which this is less troublesome.

Although the studies referred to above do not specifically mention or deal with requests for sharing, some of them do provide instances in which the transferring of an object is in fact an action of sharing it, in contrast to, say, passing or fetching it. In the latter cases the recipient of a request merely plays an intermediary role between the speaker and the object, while in the former s/he is the direct benefactor who transfers to the speaker his/her (claimed, ascribed or acquired) rights to the object. In other words, while the direct aim of requests for passing an object concerns the recipient's very action that is to be beneficial to the speaker, in the case of requests for sharing it is the relevant object itself of which the speaker aims to have direct benefit. Requests for sharing can therefore be viewed as a special domain of object requests that involve relocating the object with the right to it between the interlocutors. Consequently, although the ultimate aim of object requests concerns getting access to and using objects, the way of achieving this aim differs depending on how the material context is arranged and thus how we engage the recipient to transfer the object.

Since sharing per se involves objects and people, these two entities (i. e. artifacts and agents) built up a salient configurational structure in which agency is "materially extended" (Enfield 2017: 13). This means that for the speaker who wants to issue a request for sharing (the requester) it is relevant both what $\mathrm{s} / \mathrm{he}$ 
wants to be shared with him/her and who can perform the action of sharing. Consequently, for the recipient of the request (the requestee) it is relevant what is to be shared, who initiates the action of sharing and who is to perform it. The configuration of participation roles is complex, as it operates not only at the level of speakerhood (cf. Enfield 2013) but also at the level of event, i. e. physical sharing. If we wanted to apply the Goffmanian terms (1979) here, the requester would then be normally the author and the animator of request at the level of speakerhood and the author of sharing at the level of event. The requestee would be the author and the animator of response at the level of speakerhood, but not necessarily the animator of physical sharing. In addition, they both would share the role of the principal.

The present study explores these interdependencies by paying particular attention to the material and embodied environment and the distribution of agency in the selection of formats that serve as requests for sharing. Just as prosocial behavior has been reported to differ across cultures (House et al. 2013), the interactional practices that trigger it and the default expectations that co-occur with these practices may also reveal differences, which has already been reported with regard to requests for objects (Zinken and Ogiermann 2013). Therefore, the present study also aims to identify the moral grounds for the divergent use of syntactic conventions across Polish and Norwegian.

\section{Data and methods}

The data for this study comprise informal interactions between the participants of the Big Brother reality series in the respective languages. The reality show follows a group of people living together in a house for about three months where they do basic housework and carry out tasks in order to buy food and other goods. The Norwegian data come from the Big Brother corpus at the Text Laboratory, University of Oslo. The Polish data were collected from the first version of the Polish Big Brother broadcasted in the same period as its Norwegian counterpart in 2001. The two corpuses consist of request sequences occurring in daily interactions between 8 males and 7 females in the Polish data and between 6 males and 6 females in the Norwegian data, most of them being in their twenties and early thirties.

The character of the data is not unproblematic, but it has several advantages. Admittedly, the reality series format aims at creating a range of specific contexts intended to expose cooperation and competition between the participants by imposing externally determined aims and tasks on them. This, as well as the producer's cut, might skew the general distribution of forms. On the other hand, 
omnipresent cameras follow the participants' behavior 24 hours a day, which makes it possible to observe various, not only competitive, situations and during a relatively long period. Such long-term, experiment-like conditions enable the collection of a large number of requests as well as their contextual comparison. This is because most of the request situations concern basic here-and-now actions in comparable micro-settings, such as fetching or sharing an object or ceasing an already started action. In the case of sharing practices, requests are usually limited to the most basic goods, such as cigarettes, lighters, food or clothes.

The study employs the interactional-linguistic approach that examines linguistic phenomena in their interactional environments by combining Conversation Analysis with the functionalist perspective on language use (Couper-Kuhlen and Selting 2018). The transcriptions of request sequences follow CA conventions (Hepburn and Bolden 2013) complemented with morpheme-to-morpheme glossing. In addition, the relevant embodied actions are transcribed according to the conventions developed by Mondada (2016). The method is designed to investigate the grammatical formats as they emerge in certain configurations and identify the elements that co-participate in the recognition of requests for sharing. Thus, the multimodal interactional-linguistic approach focuses on formats' position in the sequential unfolding of events and their relation to the material and embodied arrangements.

Based on the analysis of the two data sets, requests were identified as social actions primarily aiming to get others to do something beneficial to the requester or aiming to allow the requester to do something beneficial to himself/herself. Consequently, requests for sharing goods were recognized as social actions aiming to get the requestee to relocate his/her rights to an object to the requester, either permanently or temporarily (cf. Hay 1979; Brownell et al. 2013). These rights are oriented to as a permanent, already recognized, attribute of an object (ownership) or as an ad-hoc ascribed claim to the object (possession).

Table 1 presents the distribution of requests for sharing goods together with the distribution of their grammatical formats in the two data sets. In both languages requests for sharing goods are mainly designed as imperatives or interrogatives. However, there are significant differences between the two data sets in this matter. While imperative formats predominate in the Polish data, in the Norwegian data it is the interrogative formats that are most frequent. Among interrogative constructions, ${ }^{1}$ the Can I-format predominates in both languages. Yet, while in the Norwegian data it makes up the majority of all requests for

\footnotetext{
1 The term "interrogative format" or "interrogative request" refers to the constructions that are linguistically marked as questions. Admittedly, Polish questions do not have interrogative syntax, but all requests in the data had interrogative prosody. Norwegian questions are most often marked with interrogative syntax (inversion), which was the case of all interrogatives in the data.
} 
Table 1: Distribution of requests for sharing goods, as identified in the data sets. * marks frequency of the two most frequent syntactic designs relative to all requests for sharing goods in a given data set. "Other" includes declarative and verbless constructions. In bold - the two grammatical designs analyzed in the present study.

\begin{tabular}{lrrr}
\hline & Polish & Norwegian & Total \\
\hline All requests collected & 851 & 614 & 1465 \\
Requests for sharing goods & $62(7,3 \%)$ & $41(6,7 \%)$ & 103 \\
Imperatives & $34\left(\star^{*} 5 \%\right)$ & $7\left(\star^{*} \mathbf{1 7}\right)$ & 41 \\
Interrogatives & $19\left(\star^{*} 31 \%\right)$ & $32\left(\star^{*} 7 \%\right)$ & 51 \\
Can l-interrogatives & 10 & 23 & 33 \\
Do you have-questions & 5 & 6 & 11 \\
Other questions & 4 & 3 & 7 \\
Other & 9 & 2 & 11 \\
\hline
\end{tabular}

sharing goods (56\%), it is merely used in $16 \%$ of the cases in the Polish data. Taking this into account, the relative frequency of imperatives and Can I-interrogatives in the two data sets is almost equally inverse (Polish: imperatives 55\%, Can I-interrogatives - 16\%; Norwegian: imperatives - 17\%, Can I-interrogatives $-56 \%$ ).

\section{Analysis}

This section presents the comparison of the two request formats in Polish and Norwegian. First, it describes common features or home environments (Zinken and Ogiermann 2013) of imperatives and Can I-interrogatives across the languages. Then it explores the mentioned above quantitative (along with qualitative) differences between the languages in the use of these formats.

\subsection{Sharing by giving: Imperatives as transfer requests}

In this section, I focus on the interactional properties of imperative requests for sharing goods across the two languages. In all identified instances in both data sets $(\mathrm{N}=41)$ the format was used while the requestee physically controlled the requested object or was at least presumed to be in possession of it. Thus, my main argument is that the use of the imperative that aims at getting the 
requestee to share an object is contingent on his/her controlling this object. This is exemplified in the following excerpts from the two data sets, concerning similar material goods (wigs) and situations.

In Excerpt 1 (Polish), Piotr takes a wig that belongs to one of the participants, puts it on his head and starts making faces. Klaudiusz (Klau) who is standing behind him, approaches him, reaches for the wig and utters his first request.

\section{Excerpt 1: Polish (1.011)}

01 Klau:

$$
{ }^{\star}>\text { POkaż }
$$

Show (what it looks like) for me.

klau $\quad \star \gg$ reaches for the wig--->

02

(0.9) ((Piotr continues making faces))

03 Klau: $\%$ ¡ale abędzie zajebiście*

butv be.FUT-3SG fucking.awesome-ADV look.IPFV-INF

This will look fucking awesome!

klau

fig $\quad \%$ Figure 1

piotr

04 aturns his back on klau-------------->a

klau

05 Klau:

(0.6) ((Piotr continues making faces) $){ }^{\star}($.)

$\begin{array}{ll} & \text { po\%każ. } \\ & \text { show.PFV.IMP.2SG }\end{array}$

klau -reaches for the wig and takes it--〉

fig $\quad \%$ Figure 2

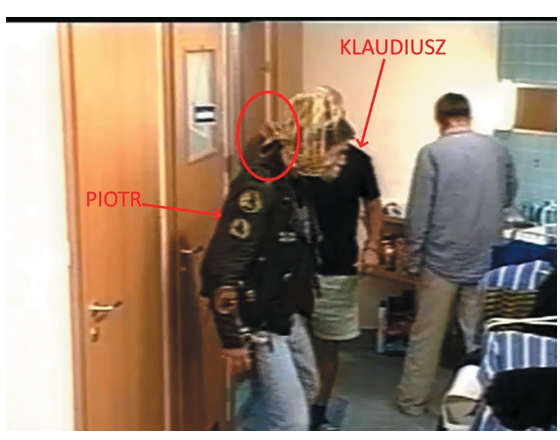

Figure 1: Prod. Endemol/TVN.

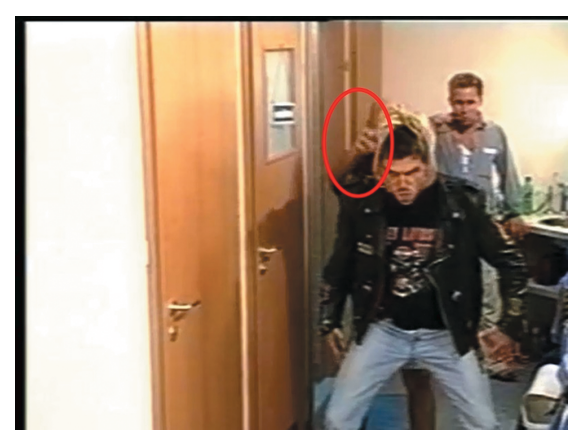

Figure 2: Prod. Endemol/TVN. 
The first imperative request Klaudiusz makes is expressed after he has started lifting his arm in order to reach for the wig. This indicates that he assumes that Piotr will comply with the request and share the object with him. One of the possible reasons is that, although the wig belongs to another participant absent from this setting, the right to use the object can be claimed on the grounds that Piotr has already been using it, i. e. the object is assumed as communally owned. Further, given the jocular character of the situation, Klaudiusz does not seem to recognize any obstacles to receiving the wig. Yet, while he is accounting for his request with a positive assessment that projects and warrants his use of the object (line 03, Figure 1), Piotr indifferently changes his position, which results in Klaudiusz' temporary withdrawal. Since Klaudiusz does not receive any reaction from Piotr, he makes a retry (cf. Mondada 2017). Here, again, the embodied action precedes the imperative (see line 04 and Figure 2) and, in the face of lacking reaction, ends in Klaudiusz taking the wig off Piotr's head.

In the Norwegian example (Excerpt 2), Lars is wearing a wig and simulating a rock guitarist when Per makes his first request and approaches him.

\section{Excerpt 2: Norwegian (2.158)}

lars $\quad$ »makes buzzing sounds and bangs his head-->

01 Per: $\uparrow$ få prøve n.

get.IMP try-INF it

Let me try it.

02

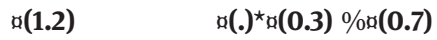

lars ------------------>^takes the wig off-->

per aapproaches larsø $\not$.............. ฉ----------->

fig $\%$ Figure 3

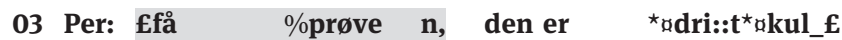

get.IMP try-INF it it be.PRS awesome

Let me try it, it's awesome.

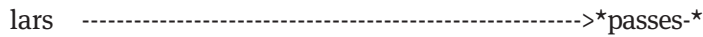

per reaches for the wig-------------------------->atakes->a

fig \%Figure 4 


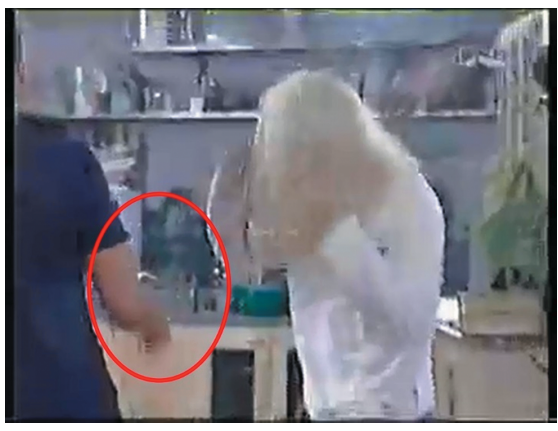

Figure 3: BigBrother-korpuset.

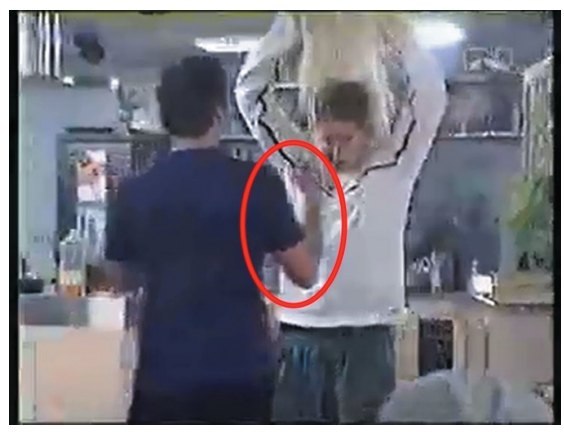

Figure 4: BigBrother-korpuset.

In this situation, Per stands away from Lars while uttering his first imperative. ${ }^{2}$ Thus, right after having made the request (line 01), he approaches Lars who starts taking off the wig. Per raises his arm (Figure 3) and repeats the imperative followed by a positive assessment (line 03) while Lars passes him the requested object (Figure 4). As in the Polish example, Per's bodily action is oriented towards a preferred response, which again may be based on several conducive premises (the wig is assumed as shared, Lars is already using it, and the situation has a jocular character). Yet, the repeated request slightly differs from the retry in the Polish excerpt, as it is used when Lars is already taking the wig off his head, which indicates that in this case the imperative rather serves to temporally navigate the requested action in real time (Mondada 2017).

What both examples have in common is that the relevant object is controlled by the requestee and the requesters' embodied actions reveal their expectation of compliance. The latter feature is in line with the interactional properties of imperatives (Craven and Potter 2010; Mondada 2017) and frequently co-occurs with this format in both data sets. Bodily orientations were directed towards either the object (glancing, extending an arm, pointing etc.) or the requestee (approaching, touching) and came right before or during the uttering of the requests. Most of the Polish requests indicated the relevant action with the imperatives daj 'give' $(\mathrm{n}=15)$, pokaż 'show' $(\mathrm{n}=11)$, also indirectly meaning

2 The Norwegian verb få belongs to the few verbs that do not make morphological distinction between imperative and infinitive. However, its syntactic and pragmatic properties in the data speak for its imperative function rather than the infinitive (see Faarlund 1985; Johannessen 2016). 
'give', and zostaw 'leave' ( $\mathrm{n}=4$ ). Importantly, apart from two instances responsive to actions going counter to the requester's expectations, the Polish imperatives were formed in the perfective aspect claimed to display the authorship of action (here sharing) as the requester's right (Zinken 2016). In the Norwegian data, all the instances were formulated with the verb $f a ̊-$ either directly meaning 'receive' or combined, as a permissive auxiliary, with the verbs se ('see') and prøve ('try'). ${ }^{3}$ The use of $f a ̊$ is particularly interesting, as it semantically highlights the requester (beneficiary) while covering the requestee (benefactor) as the performer of sharing ${ }^{4}$ (see also Sections 5.3 and 6).

Although imperative requests are often embedded in on-going joint projects (Rossi 2012; Zinken and Ogiermann 2013), their use in requests for sharing objects does not always go hand in hand with these conditions. Nor does it necessarily concern shared goods which might warrant the requesters' rights to them. What the data show is rather that the imperative marks that the requester does not orient to any contingencies for granting his/her request even though $\mathrm{s} / \mathrm{he}$ is not the exclusive owner of the object. This seems to be anchored in his/her evaluation of and orientation to the premises that are considered conducive enough to expecting compliance and, consequently, to the requestee's potential willingness to share. This means that joint activity and/or urgency are merely some of the conducive premises that make the basis for the assumption that the requestee can or should share the relevant object. The next two excerpts exemplify this claim.

In Excerpt 3 (Polish), Małgorzata (Małgo) walks outside, smoking a cigarette, and heads towards Manuela who is sitting at the corner of the yard. In lines 0102, Małgorzata makes a negative assessment of the recent events in the house and receives an affiliative response from Manuela (line 04) marked with the prolonged $e$ in wiem ('I know') and the final fall. Then, while sitting down on Manuela's knees, she is asked for a puff (line 08).

3 One instance is the modal construction la meg få, meaning 'let me have'. It is likely that the fá-imperative might have evolved from the la meg fä-construction, as its elliptical variant, although with a slightly different pragmatic function. Thanks to Jan Svennevig for pointing this out to me.

$4 \mathrm{Få}^{\circ}$-imperatives have been claimed to be first-person imperatives in Norwegian (Faarlund 1985). The data indeed shows examples in which the participants treat them so by marking the first person in right-dislocated components, as in Få se, jeg óg ('Let me see, me too'), but see also Excerpt 4 where the requester modifies the request with er du snill ('are you kind') which refers to the imperative as being in the second person. 
Excerpt 3: Polish (2.195)

01 Małgo:

$\begin{array}{llll}{ }^{\star 0} \underline{w i}^{\circ} \mathbf{d z i s z} & \text { manuela }_{\boldsymbol{i}}(\mathbf{0 . 6}) & \text { te } & \text { dzisiejsze } \\ \text { see-2SG } & \text { NAME } & \text { these } & \text { today.ADJ-PL } \\ \text { You see, Manuela. These today’s }\end{array}$

małgo *»walks---->1.6

02

$\begin{array}{llllll}\text { niespodzianki } & \text { wcale } & \text { ni:c } & \text { dobrego } & \text { nie } & \text { narobily. } \\ \text { surprise-PL } & \text { at.all } & \text { nothing } & \text { good-GEN } & \text { NEG } & \text { PFV-do-PST-3PL } \\ \text { surprises did not do anything good. } & & & \end{array}$

03

(1.6)

04 Manuela: (t/no) wie:m.

(this) know-1SG

I know (that).

05

(1.3)

06 Małgo:

wychodzi na to.*

come.out-3SG on this.ACC

It turns out.

07

małgo

(0.6)

-->^sits down on Manuela’s knees->

08 Manuela: $\downarrow$ da:j macha:.* hyhyhyhyhyhyhyhy.

give.PFV-IMP.2SG puff-ACC

Give a puff. Hee hee hee hee hee hee hee hee.

małgo

Małgorzata's negative assessment that Manuela affiliates with becomes a point of departure for the turn in line 08. This is marked by the way Manuela utters her request. Pitch fall and the lengthening of the vocal in the imperative mark that she identifies with Małgorzata's affective stance and regards this as a sufficient reason for having a puff as a consolation. However, through the laughter that comes right after the request she reveals the non-seriousness of her entitlement. Yet, what seems crucial in this situation is that seeing Małgorzata with a cigarette and responding to her assessment, Manuela builds a link between the material and the sequential configuration that allows her to direct the focus on the very action of sharing.

In Excerpt 4 (Norwegian) Lars and Rodney sit on the sofa and talk. Rodney smokes a cigarette that he has already shared with Lars once. Now, after they have been sitting in thoughtful silence for a while, Lars requests for the cigarette again. 
Excerpt 4: Norwegian (2.004)

01 Lars:

$\begin{array}{lcccc}{ }^{\star} \uparrow \mathbf{f a ̊} & \text { et }^{\star} & \text { sånn (0.3) } & \text { ting (.) } & \text { \#til\#. } \\ \text { get.IMP } & \text { ART.N } & \text { such.M } & \text { thing } & \text { to }\end{array}$

(Let me) receive this thing one more time.

$\mathbf{0 3}$ rodney

*...... *pointing-->

$a(0.6) a(0.3)$

a...........atakes a drag-->
$\# \uparrow$ du\# snill.

be.PRS you kind

Are you kind.

$04 \quad$ (1.0)

05 Rodney: .hhh $a(0.4)>$ p(h)a:ss it $0^{\star}: a:: n .<$

Pass it on.

rodney $\quad$--> apasses the cigarette->a

lars

$>\star$ takes the cigarette-〉

Knowing that Rodney has already shared the cigarette with him, Lars has at least one reason for expecting compliance. In the context of their cozy chat, he does not seem to orient to any obstacles at first, which is also confirmed with his embodied action synchronized with his verbal conduct. Yet, after having uttered the request, he is not granted it immediately, as Rodney first takes a drag on the cigarette before passing it to Lars. In the meantime, Lars adds the request marker er $d u$ snill 'are you kind' (line 03) to his request. Considering the delay in the compliance (line 02), this move seems to indicate that the only potential obstacle that emerges at the very moment might be Rodney's willingness to share.

In this section, I have provided evidence that the use of imperatives as requests for sharing goods is a result of a specific material and contextual configuration. My claim is that imperative requests for sharing are chosen when the requestee is in (usually physical) control of the object and when the requester does not orient to any contingencies for expecting compliance, nor is the exclusive owner of the object. The second condition may result from either joint engagement in a project or from any conducive premises. Now, given the lack of assumed contingencies and the manifest control of an object, what the imperative format by default seems to orient to is the very action of transferring this object (cf. Etelämäki and Couper-Kuhlen 2017) as a domain of the requester's authorship and the requestee's animation of the event, both parts being somehow responsible for the sharing. This is reflected in the format's grammatical composition. Verbs were rarely followed by the direct 
object in Polish (cf. Extract 1$)^{5}$ or by a specified object in either of the languages. Put differently, because the requested object is normally already manifest to the requester as being in possession of the requestee, the conceptual locus of imperative requests is not so much possession as transfer. This and the distribution of agency also agree with the verb semantics and the deictic marking in Polish imperatives that usually indicate the action in the second person and in the perfective aspect. Agency distribution did not however match the Norwegian imperative which for the action of sharing took on the verb $f a$ ('receive') and thus manipulated the agency roles by highlighting the requester as a quasi-animator of the event.

\subsection{Sharing by permitting: Can I X? as a permission request}

The class of Can I-interrogatives in the data consists of two configurationally divergent conventions of use: permission and transfer requests. In this section, I focus on the first one. In 18 ( $n=8,80 \%$ from the Polish data and $n=10,43 \%$ from the Norwegian data) out of all 33 instances the format was used when the requester him-/herself took action on the relevant object, seeking permission to make use of it. In such situations, the requestee was normally not in the direct control of his/her possession, that is, the requestee did not hold the object, stood away from it, or was occupied with an activity that hindered any physical management of the object. Thus, my main argument is that the choice of Can Iinterrogatives as requests for permission is normally contingent on the requester's acting on the object owned by the requestee who is not controlling it physically at the time of requesting. The following excerpts illustrate this claim.

In Excerpt 5 (Polish), Monika and Małgorzata (Małgo) are preparing for a live broadcast, doing make-up and arranging their hair. At some point Monika begins to look for a comb, wiggling her fingers. After having noticed the one that belongs to Małgorzata, she heads towards the place where it lies (Figure 5), simultaneously making a permission request (line 03).

\section{Excerpt 5: Polish (2.012)}

$\begin{array}{lll} & \text { monika } & \star \\ 01 & \text { Monika: } & \text { \#m::.\# } \\ & & \text { Mhm. } \\ & & (\mathbf{0 . 8})^{\star}\end{array}$

5 In Norwegian syntactic relationships are tighter than in Polish, the object being required as one of the core arguments of the verb. 
03 Monika:

$\begin{array}{lcc}{ }^{\star} \text { moge } & \text { twojego } & { }^{\star} \% \text { grzebienIA? } \\ \text { can-1SG } & \text { your-GEN } & \text { comb-GEN } \\ \text { Can I (use) } & \text { your comb? } & \end{array}$

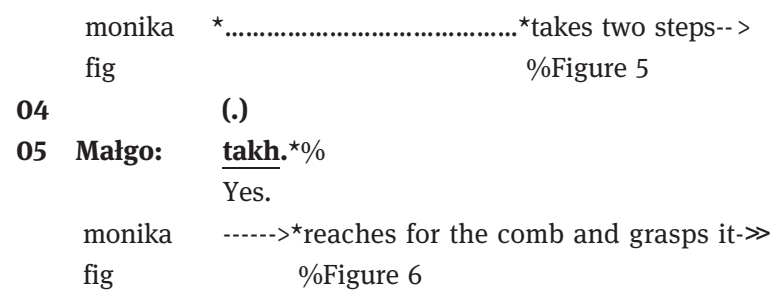

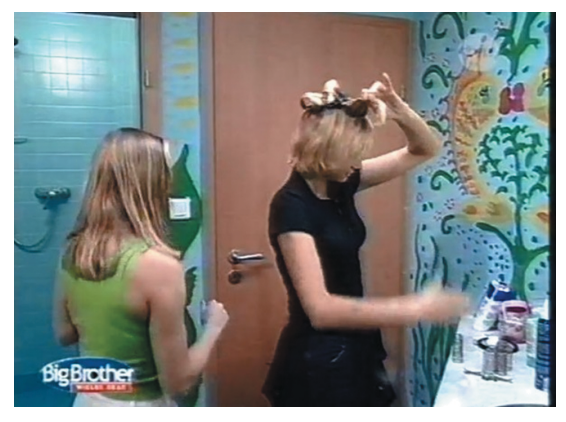

Figure 5: Prod. Endemol/TVN.

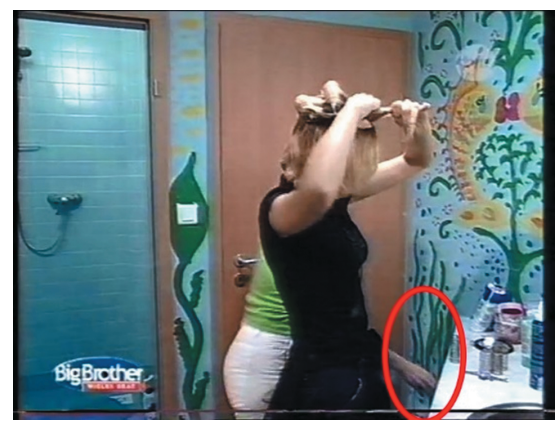

Figure 6: Prod. Endemol/TVN.

Knowing that Małgorzata is occupied with arranging her hair, Monika decides to take action on the object by herself. Through her embodiment, she reveals that she does not seem to orient to any obstacles that would hinder the use of Małgorzata's comb, as she is already on her way to grasp it while making her request. Still, she does ask for permission by forming an elliptical modal interrogative Moge ('Can I') followed by the direct object in genitive that implicates that she wants to make use of the indicated object. Thus, what Monika seems to orient to with her request is the fact that the comb is owned by Małgorzata and the use of it needs the latter's permission even if the former does not expect refusal in this matter. Consequently, ownership becomes the contingency that seems most relevant to Monika at the moment of requesting.

The Norwegian example (Excerpt 6) presents a similar situation. The participants sit on the terrace and talk. Monika agrees to share with Anita the last place in a competition and explains her motivation (lines 01 and 02). Rodney comes with an acknowledgment token in line 04, displaying understanding and 
establishing an ultimate agreement. During a one-second pause Monika grasps a bottle that stands on the armrest next to Anita, and while lifting it (Figure 7), she asks Anita for permission to have a sip of her drink (line 06).

\section{Excerpt 6: Norwegian (2.056)}

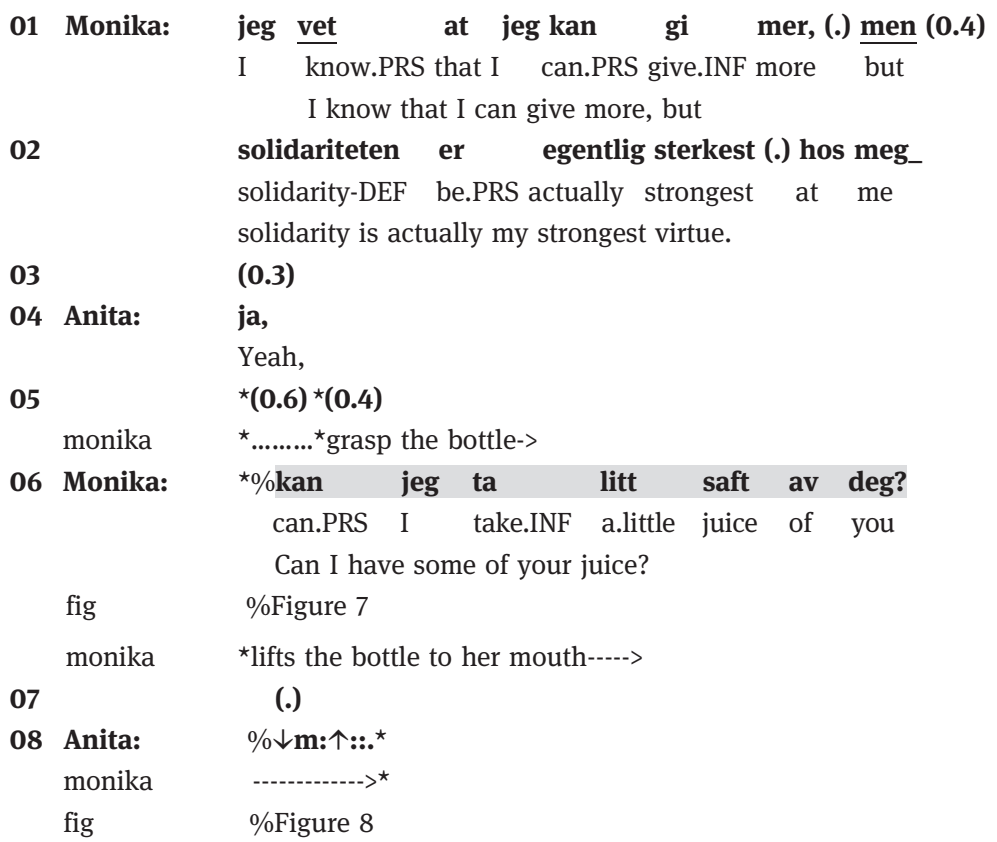

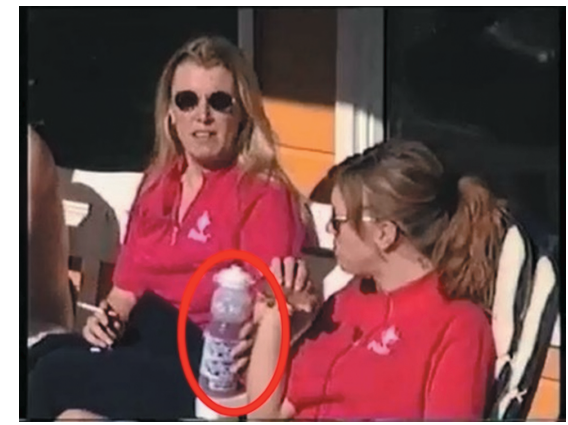

Figure 7: BigBrother-korpuset.

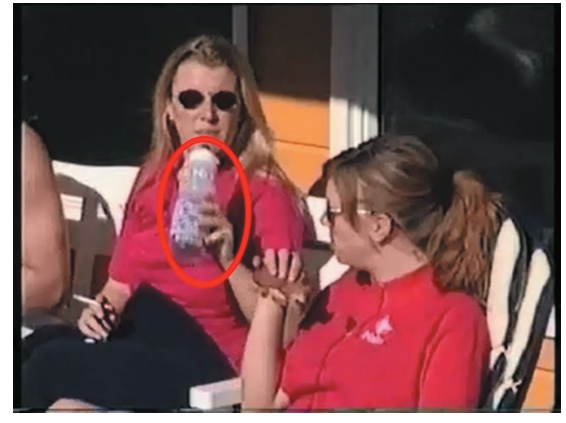

Figure 8: BigBrother-korpuset. 
When Monika is reaching for the bottle, Anita is not controlling it directly, as she is eating a sandwich. The moment at which Monika grasps the bottle happens four tenths of a second before she makes her request. Then, she lifts the bottle to her mouth just as she begins to produce the interrogative Kan jeg ta ... 'Can I take ...' (line 06), gazing at Anita. The action is smooth and perfectly timed with the whole adjacency pair. Put differently, Monika does not wait for the answer by ceasing or delaying the lifting, which provides evidence that she expects the response to be positive. In the meanwhile, she nevertheless asks Anita for permission, additionally downgrading the format with the indefinite quantifier litt ('a little'). This demonstrates that she is not only aware of and orients to ownership, but also recognizes the potential disadvantage to Anita, as the latter will inevitably have less drink afterwards.

In both situations, the requesters project acceptance through their embodied actions, but at the same time they ask for permission to use the relevant object. This paradox constitutes a predominant pattern in the data, revealing two divergent, although complementary, trajectories of interactional conduct. The first one is directed towards the relevant object in the context of premises conducive to expecting acceptance. The second one is directed towards the requestee and his/her right to the object that is recognized by the requester. Now, what are the situational premises that might entitle the requesters to act on the object by taking it? In Excerpt 5 it might be the very fact that although each of them does her own thing, they together construct a joint make-up activity that warrants certain expectations and actions. Consequently, Monika may expect that Małgorzata will let her use her comb in the lack of any other and the request indeed announces this lack apart from explicitly acknowledging ownership. Moreover, the fact that Małgorzata is occupied with her own activity might also prompt Monika's decision to take action on the comb rather than to recruit Małgorzata to pass it. In Excerpt 6 Monika's entitlement is less transparent. However, her action is preceded by her decision that puts an end to a misunderstanding that had occurred between her, Anita and the others. In addition, several other details seem to harmonize here: the object's character (its scarcity is only temporary), the object's location (the bottle is at hand), and Anita's engagement in eating a sandwich.

The second trajectory, oriented to requestee's ownership, is related to a shift in agency. Contrary to the situations from the previous section, in these cases the requester becomes, in Goffman's (1979) terms, both the author and the animator of the event, while the requestee remains the one that grants permission and carries co-responsibility for sharing. Thus, the requester's decision to take action on the object, conditioned by various premises, triggers the need to recognize and acknowledge the requestee's ownership by seeking permission to 
use the object. In other words, the relocation of animation makes ownership a salient point of reference used to authorize the already taken or planned action. This is because the transfer of possession is not automatically authorized by the decision and/or the action of the possessor, as it is the case with imperative requests. The grammatical design with a first-person deictic perspective reflects this shift in the distribution of agency, getting the requestee to respond, which is in fact the case in all instances in the data but one. ${ }^{6}$ In the Norwegian data, most of the interrogatives employed the verb ta ('take'), alternatively låne ('borrow'), as an action verb. ${ }^{7}$ In the Polish data, the interrogatives additionally had a specific word order. If the object was mentioned ( 4 out of 8 cases), it followed the modal verb moge ('can-1SG'), but preceded the main, infinite verb, according to the scheme $\mathrm{V}_{1}+\mathrm{O}\left(+\mathrm{V}_{2}\right)$. In terms of information structure this pattern reveals that an object may often receive prominence over an action, which is even more evident when $\mathrm{V}_{2}$ is omitted.

To sum up this section, a large number of Can I-interrogatives in Polish and Norwegian were used when the requesters took action on the object that did not belong to them. They most often did it before or simultaneously with their verbal conduct, revealing that they expected acceptance from their requestees. The Can I-interrogative was in all these cases a request for permission that revealed the requester's orientation to ownership as a way of recognizing and acknowledging the requestee's agency and thus, through the requirement of response, authorizing the requester's action on the object. Consequently, the conceptual locus of this kind of interrogatives is object ownership (as a potential contingency) rather than the action of sharing since the latter is grammatically and bodily displayed as the requester's domain of performance.

\subsection{Borderline format: Can I X? as a transfer request}

The remaining class of interrogatives reveals different configurational properties as well as cultural differences between the Polish and the Norwegian way of making requests for sharing. 2 Polish (20\%) and 13 Norwegian (57\%) Can Iinterrogatives were used when the requestee was in control of the relevant object. This demonstrates that in both languages interrogatives are also employed to get the requestee to share an object by transferring the thing that $\mathrm{s} /$ he controls or is presumed to do so. However, while this seems to be a

6 In the remaining case, there was no explicit response from the requestee but a question on another issue, which the requester construed as a lack of refusal.

7 In the Polish data, the second verb was often omitted. 
prevalent pattern of getting others to share goods in Norwegian, in Polish it is marginalized by the frequent use of imperatives in similar contexts, hence the distributional differences (see Section 4). In this section, I characterize the syntactic and interactional features of transfer Can I-interrogatives. I focus on two material configurations: when the object lies near the requestee who is using it and when the object is held by the requestee.

In Excerpt 7 (Polish), the participants are sitting around the table and painting Easter eggs. Piotr, who is sitting at the end of the table with a hood on his head (see Figure 9), asks Małgorzata (Małgo) to pass the blue paint that she is using (line 01).

\section{Excerpt 7: Polish (2.252)}

01 Piotr:

$\begin{array}{lllll}\text { gosia } & \text { da- } \text { dasz } & \text { mi } & \text { niebieską } & \text { farbę } \\ \text { NAME.DIM } & \text { give.PFV-FUT.2SG } & \text { me-DAT } & \text { blue-ACC } & \text { paint-ACC } \\ \text { Gosia, will you give me the blue paint? } & & \end{array}$

02

(0.4) proszę,

request.IPFV-1SG

please?

03

(1.9)

04 Piotr: gosiu.

NAME.DIM-VOC

Gosia.

05

(0.2) *(.)

małgo

*turns her head-->

06 Małgo: proszęi

request.IPFV-1SG

Yes $i$

07

(0.3)

08 Piotr:

oniebieøską *farbę mogę?\%

blue-ACC paint-ACC can-1SG

The blue paint can I (have)?

piotr anods->a

małgo ---------------->^reaches for the paint-->

fig

09

(0.2)

10 Małgo: [p $r$ o $* \begin{array}{cccc}\mathrm{s} & \mathrm{z} & \mathrm{e} & \text {.] }\end{array}$

request.IPFV-1SG

Here you are.

małgo

--------->^relocates the paint-->10.15

11 Piotr:

[>od ciebie?< ]

from you.GEN

From you? 


\begin{tabular}{|c|c|c|}
\hline 12 & & (0.4) \\
\hline \multirow[t]{2}{*}{13} & Małgo: & tak. \\
\hline & & $\begin{array}{l}\text { Yes. } \\
(\mathbf{0 . 5 )}\end{array}$ \\
\hline 15 & Piotr: & $\%{ }^{\circ}$ dzięki, ${ }^{\circ \star}$ \\
\hline & & Thanks, \\
\hline & małgo & - \\
\hline & fig & \%Figure 10 \\
\hline
\end{tabular}

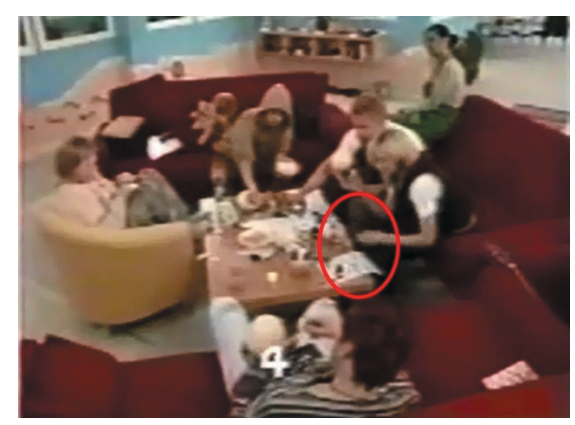

Figure 9: Prod. Endemol/TVN.

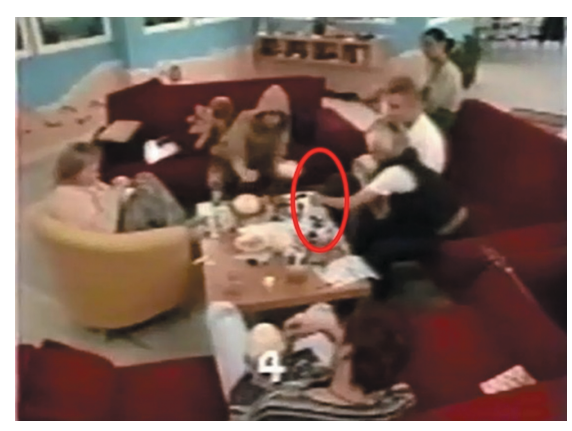

Figure 10: Prod. Endemol/TVN.

Because Piotr does not receive any response to his first request (lines 01-02), he summons Małgorzata with her diminutivized name in vocative (line 04) and after her reply in line 06, he makes a retry (line 08). This time, however, he reformulates the request by changing the format from a polar second-person question in the future perfective ( $\approx$ 'Will you X?') to an elliptic polar question in the first person singular ('Can I X?'). This shift marks a change in his orientation to the details of the material configuration. While the first request simply serves to recruit Małgorzata to pass the object that lies near her and thus can easily be relocated by her, the second request, uttered in the lack of response but aiming at the same action, clearly masks Małgorzata's animatorship of sharing. This is manifest in two orientations marked in the grammatical design of the format: the requester as an as-if animator (marked with the grammatical first person) and the acknowledged object possession as the requestee's attribute (marked with the modal verb can and the indirect object in line 11). Consequently, by choosing this construction when Małgorzata is in possession of the object, Piotr both recognizes her right to this object (as permission Can I-interrogatives do) and gets her to share it by passing it (as imperatives do). The former orientation might become relevant in the face of the obstacles that arise. After all, 
Małgorzata is not only occupied with her own activity, but is using the blue paint, which Piotr might realize after his first request. In other words, given the condition that the requestee is in control of the relevant object in question, Can I-interrogatives look like permission requests, but behave like imperatives (see 5.1; cf. Zinken 2015), yet oriented to possession.

This borderline feature of the format is even more explicit in the Norwegian example below (Excerpt 8). Anette and Ramsy are sitting on the terrace and talking. Anette smokes a cigarette and asks Ramsy questions about his roots and family. When she finds out that he has grown up in Norway, but his family comes from Palestine, she asks another question (lines 01-02).

\section{Excerpt 8: Norwegian (1.103)}

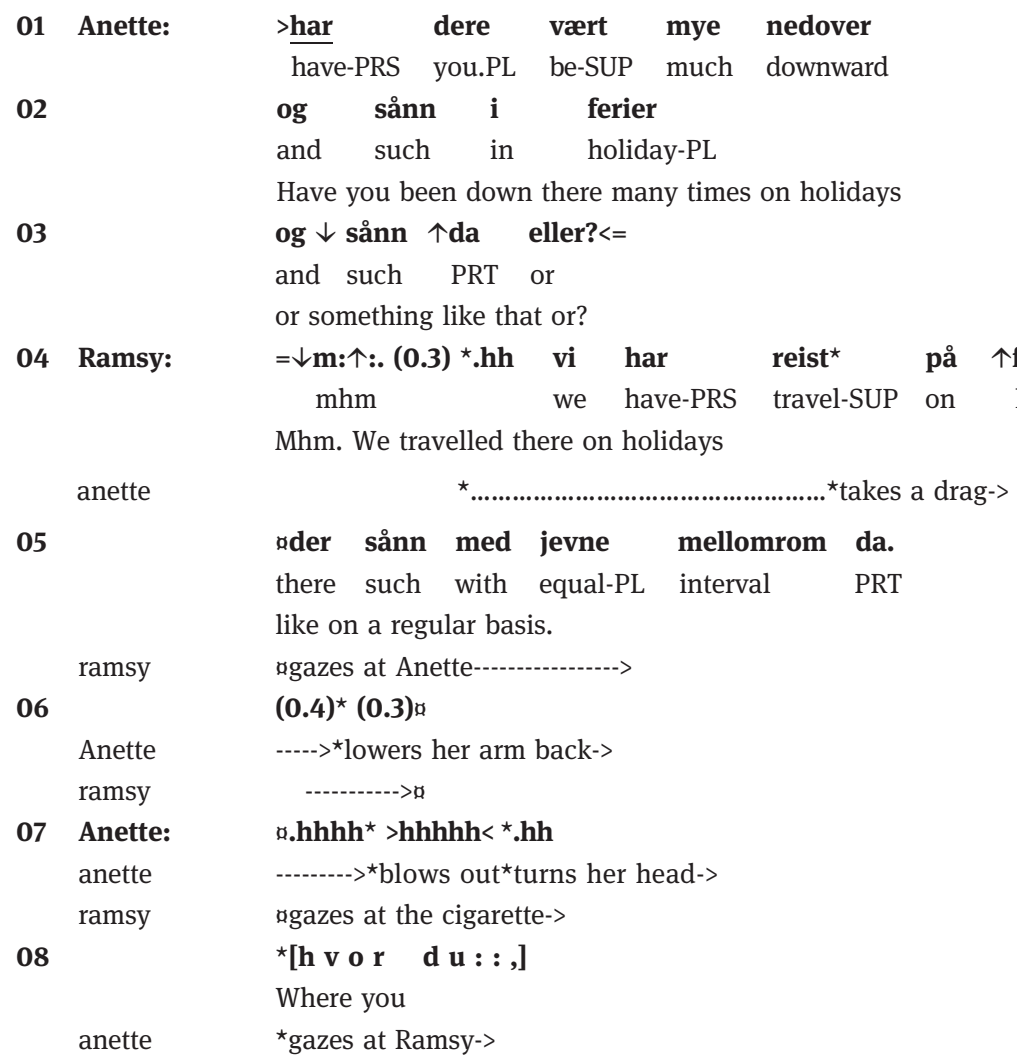




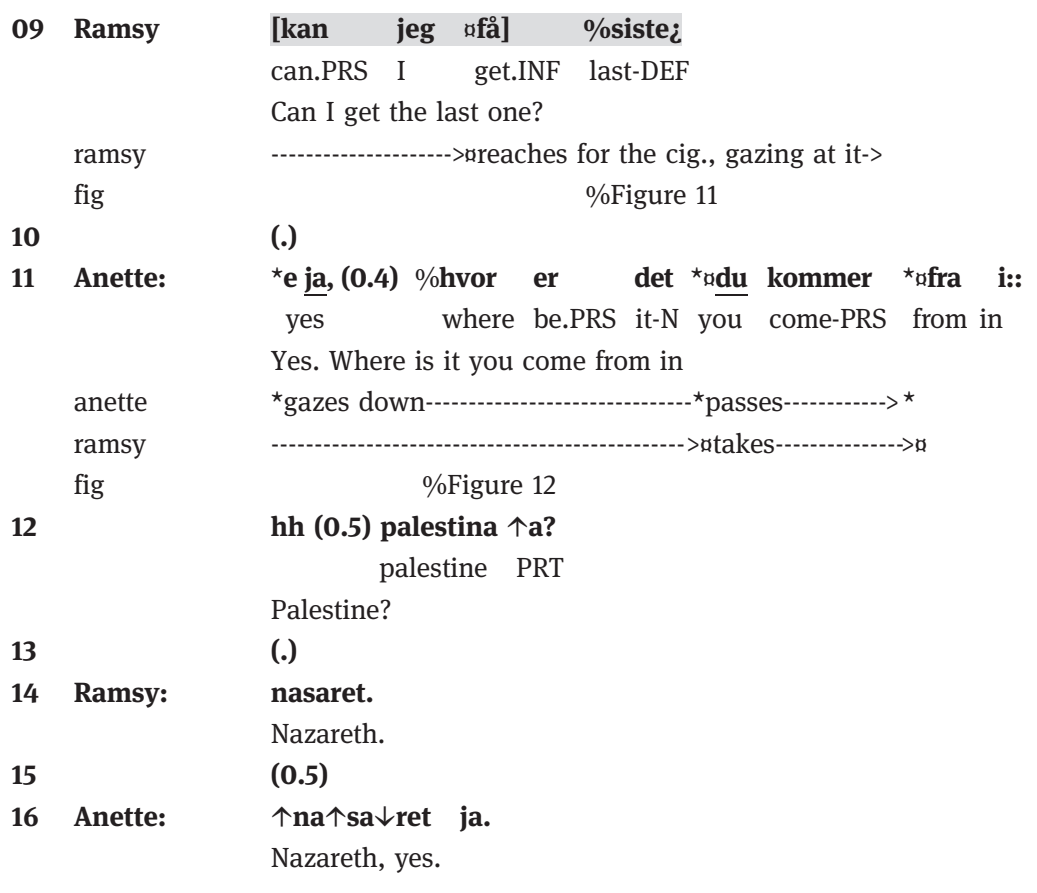

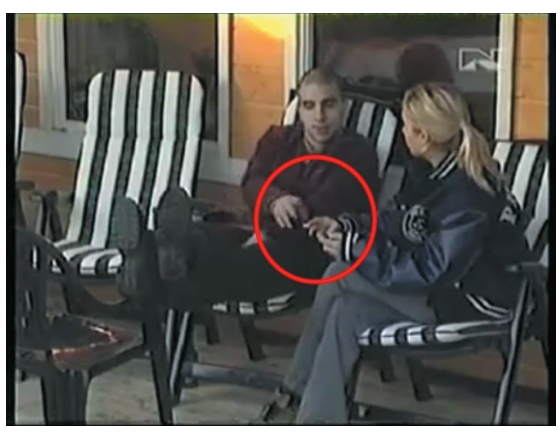

Figure 11: BigBrother-korpuset.

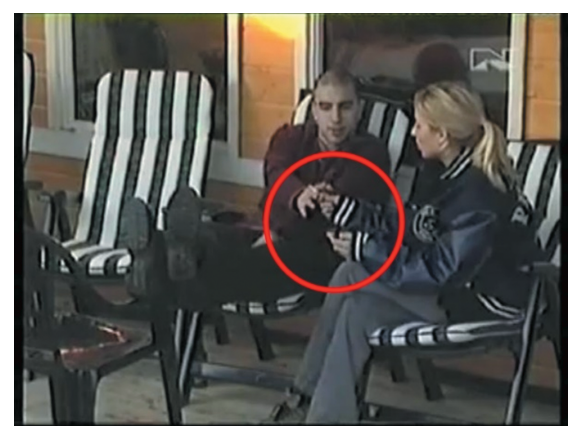

Figure 12: BigBrother-korpuset.

While Ramsy is replying to Anette's question in lines 04-05, she takes a drag on the cigarette. Just as she lowers her arm back on the armrest and blows out the smoke, Ramsy moves his gaze from her to the cigarette, which indicates that he checks availability. This allows him to prepare the next turn, which is designed as an interrogative request Kan jeg få ('Can I get'). While uttering it, he stretches his arm forward (line 09, Figure 11), clearly demonstrating that on the basis of 
his situational assessment, he assumes high probability of compliance. The turn overlaps with the next question Anette starts asking (line 08), which eventually results in her leaving the floor. After the Can I-interrogative is produced, Anette replies with an acceptance token and returns to her question, simultaneously complying with the request (line 11).

Contrary to the Polish example (Excerpt 7), Ramsy and Anette are engaged in their own conversation, sitting in the proximity of each other. These preconditions facilitate the coordination of embodied moves that project and conduct the granting of the request, as it was also the case in Excerpts 2 and 4. So the question is: Why does Ramsy use a Can I-interrogative in this case and not an imperative, as Lars did in Excerpt 4? Although these two examples are similar, the contextual premises are slightly different. Here Anette did not share the cigarette with Ramsy before and he actually asks if he can smoke it to its end. Consequently, although he bodily reveals that he expects compliance probably based on some conducive premises (e.g. cozy chat), he does not seem to have strong enough reasons to assume that the transfer of possession is fully warranted, which might be the case in Excerpt 4. Thus, the use of Kan jeg få conventionally marks the acknowledgment of Anette's right to decide on the object in spite of Ramsy's explicitly manifested expectation of compliance. Importantly, by responding verbally, Anette also seems to treat Ramsy's request as orienting to her possession.

A crucial detail is the grammatical design of this type of Can I-interrogatives in Norwegian. ${ }^{8} 12$ out of the 13 instances include the verb få ('receive') ${ }^{9}$ which explicitly manipulates the distribution of agency at the level of event by presenting the requester (beneficiary) as a passive animator of sharing, thus masking the animatorship of the requestee (benefactor). A shift in the distribution of agency is the feature embedded in the grammatical design of Can I-requests in general. The only difference is that this shift is real in the case of permission Can $I$-requests but virtual in the case of transfer Can I-requests. This also seems to be reflected in positive responses to these formats: Permission interrogatives normally receive verbal replies necessary to authorize the requester's action while transfer interrogatives are often followed by merely non-verbal responses

8 The Polish data consist of too few examples to characterize the grammatical design of transfer Can I-requests. The two examples in the data include the elliptical Can I and the same construction with the infinite performative verb prosić ('request'). Yet another possibility is mentioned by Zinken (2015).

9 The remaining instance includes the verb låne that apart from receiving ('borrow'), cf. 5.2, also denotes giving ('lend') and thus can be used to mark passive animatorship. 
(compliance) which automatically authorize the requester's expectations (cf. imperatives in Section 5.1; Zinken 2015).

In this section, I have demonstrated that a number of Can I-interrogatives are used to ask the requestee to transfer the object $\mathrm{s} /$ he controls to the requester who does not own it exclusively. I have shown that this particular material configuration is what makes them different from permission requests and similar to imperative requests for sharing since the latter also require the requestee be in control of the object so as to (co-)conduct its relocation. Yet, as opposed to imperatives, Can I-interrogatives as requests for transfer orient to the requestee's right to decide on the object in the face of the premises that go counter the requester's projection or do not provide strong enough reasons to assume sharing as warranted. Put differently, possession is in the case of imperatives a necessary condition for the recognition of action in spatio-material configurations (e. g. sharing vs. passing or fetching), while in the case of interrogatives it also serves as a salient point of reference used to seek the authorization for own action (permission requests) or expectations (transfer requests).

\subsection{Cross-cultural differences}

As I mentioned above, the Polish and the Norwegian data differ in terms of formats chosen to make transfer requests for sharing (i.e. imperatives and transfer Can I-interrogatives). The collection made for the present study indicates that the Poles preferred using imperatives to recruit others to share goods, while the Norwegians tended to choose the Kan jeg få-format unless the requester had strong reasons to use an imperative. This could be observed in the analysis of similar sequential environments across the languages in which different formats were employed. In this section, I focus on two such environments: 1) when a request comes after the disclosure of an object, and 2) when it comes as a reaction to resistance. I demonstrate that the assessment of contingencies differs across the two languages in the weight that is given to them. My claim is that the imperative is the default format used as a request for sharing in Polish in the lack of strong enough premises that threaten compliance, while the transfer Can I-interrogative is the default format used as a request for sharing in Norwegian in the lack of strong enough premises that warrant the use of an imperative. In other words, while the Polish participants seemed to need good reasons to select Can I-interrogatives, their Norwegian counterparts seemed to need good enough reasons to choose imperatives. The following excerpts exemplify my claim. 
In Excerpt 9, Klaudiusz (Klaudi), who came back to the house of Big Brother, announces that he has smuggled chewing gum (line 01), gazing at Manuela. Right before this, he has been warned that he must not reveal information from the outer world. He receives two overlapping responses: Manuela's unintelligible reaction (probably a comment) and Janusz' request in the perfective imperative (line 04).

\section{Excerpt 9: Polish (2.189)}

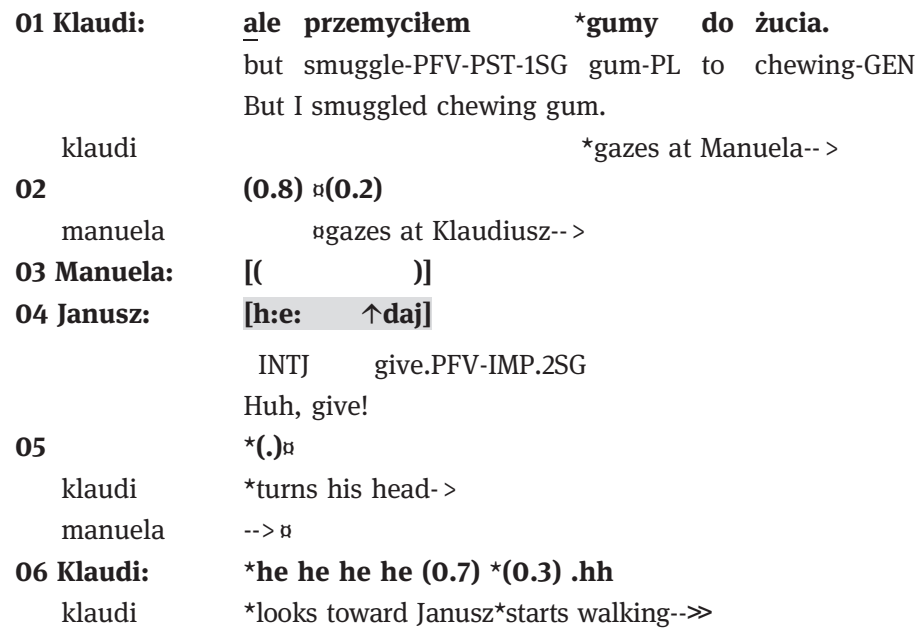

The preface ale ('but') in line 01 marks that the announcement responds to the admonition by marking contrast between the fact that Klaudiusz cannot reveal any information and the fact that he managed to bring the gum secretly. This reveals his ironic stance towards his own achievement and its significance. The central part of this "announceable news" (Terasaki 2004) is the specified, sharable object being in the requestee's possession. By making it manifest to others, Klaudiusz opens the possibility to share it and thus validates the following request as a reaction. Janusz' imperative request seems therefore warranted: Since Klaudiusz discloses the object, he can be assumed to be willing to share it and thus he can be requested to do this. Yet, the imperative format marks one more thing: Janusz does not orient to any contingencies. This may be motivated by the conducive premises Klaudiusz creates with his announcement, but also by subjectively too weak counter-premises, such as the distance Kladiusz has to cover in order to share the gum with Janusz who is lying on the sofa in the next room.

The Norwegian example in Excerpt 10 demonstrates the requester's different choice of request format, as compared to the Polish sequence. Here, Lars 
jokingly comments on the intimate situation between two participants that he and Roy have already witnessed. In his comment, he reveals that he is in possession of a chocolate, which triggers the first request on the part of Roy (line 04). However, Roy's request remains unanswered (probably because it comes up when Lars has already prepared his next turn and starts to utter it), which is why he makes a retry in line 08 while standing up and moving towards Lars.

Excerpt 10: Norwegian (1.133)

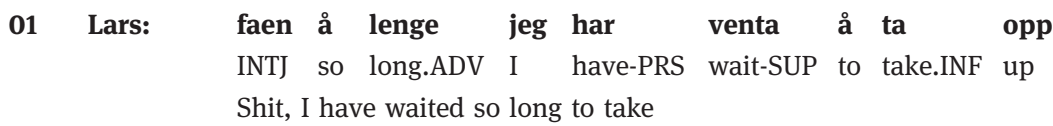

$$
\begin{aligned}
& \text { den stratosen nå.< } \\
& \text { that NAME-DEF now } \\
& \text { this Stratos chocolate. }
\end{aligned}
$$

03

(2.3) ((laughter in the background))

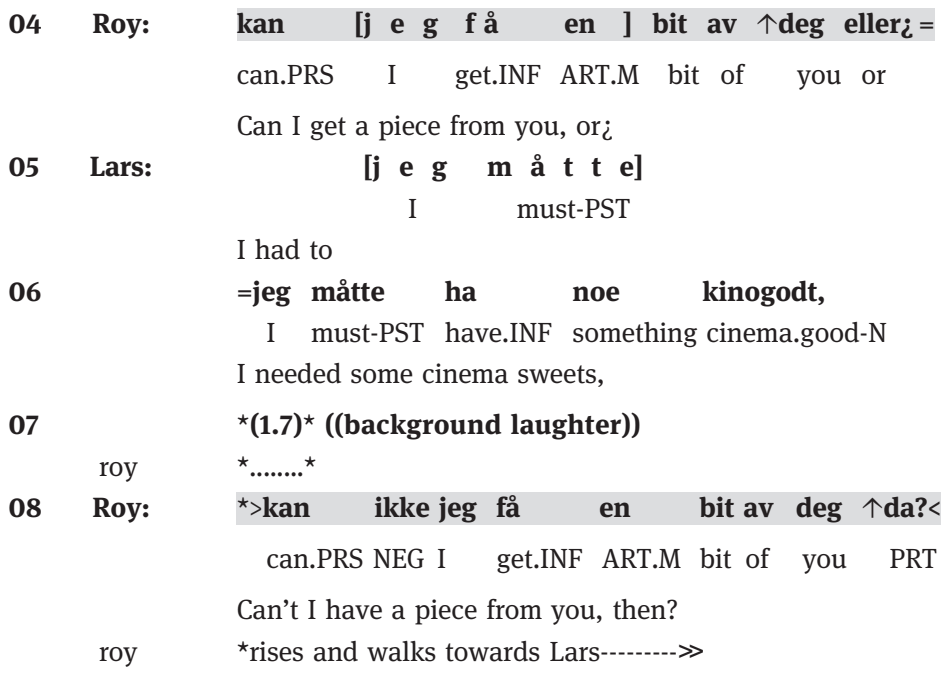

The disclosure of object in this situation is admittedly done through a slightly different action than in the previous example. Lars' comment is self-oriented, which does not make a request for sharing a relevant next as easily as it was in the case of Klaudiusz' announcement. This already creates a potential obstacle of which Roy may be aware. The positively framed Can I-interrogative with the final particle eller ('or') indexes his orientation to contingencies and uncertainty about the granting of request. However, when Roy makes a retry, he bodily reveals that 
he expects compliance by approaching Lars and reaching for a piece of chocolate. His expectation is also marked in the changed format. The negatively framed interrogative with preposed negation demonstrates that compliance is anticipated and obstacles are considered as merely hypothetical (Urbanik and Svennevig 2019). Nevertheless, the grammatical matrix of his request (the interrogative) remains unchanged, which shows that despite the premises that Roy might assess as conducive, Lars' willingness to share is by no means taken for granted. In other words, these premises seem not strong enough to prompt him to claim entitlement and use an imperative format (e.g. Få en bit - 'Let me have a piece').

The next two excerpts demonstrate that even in the face of the requestee's resistance the choice of request format may reveal sharp differences between Polish and Norwegian. In Excerpt 11 (Polish), Sebastian is talking to another participant at the end of the room while waiting for Piotr to go out and smoke with him. Seeing that Piotr takes just one cigarette, Sebastian, who has run out of his own cigarettes, tells Piotr to take two.

\section{Excerpt 11: Polish (1.165)}

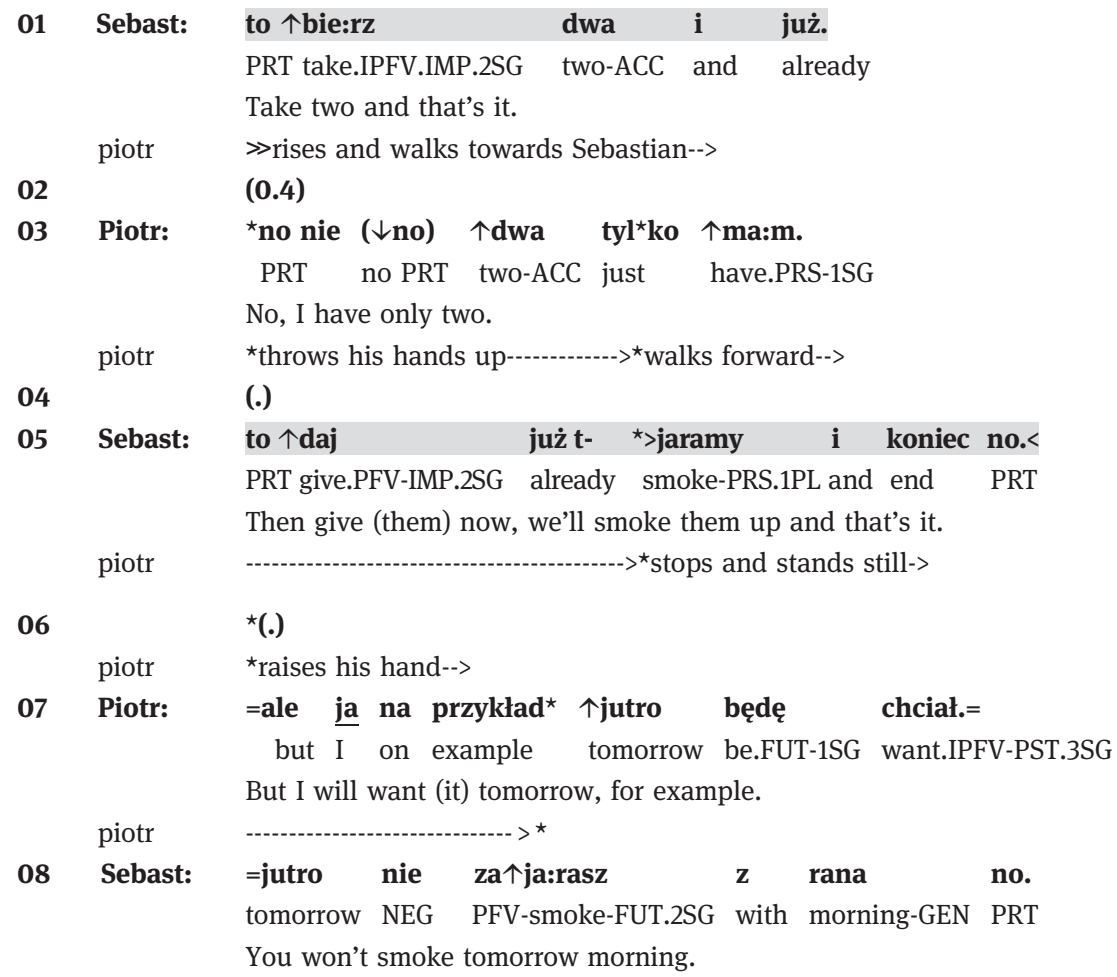


09

10
(0.5)

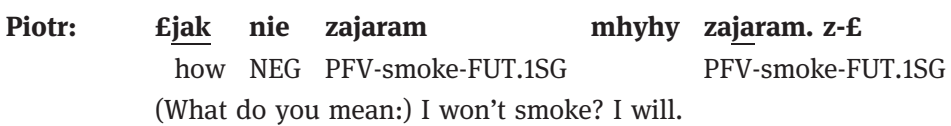

The first request is formulated as an imperfective imperative of the verb brać ('to take') with the vowel stretched. The selection of this form is claimed to direct the animation of an action without claiming its authorship that is already the property of the requestee (Zinken 2016). Here, Piotr has already taken a cigarette and Sebastian's role is merely to change Piotr's decision on the number of cigarettes that should be taken. This indeed means affecting the animation of the action in a begging manner and encouraging immediate compliance (a prompt), hence the vowel lengthening and the terminative phrase $i j u \dot{z}$ ('and that's it'). Yet, after the refusal in line 03, Sebastian makes a second attempt, but reformulates the request as a perfective imperative of the verb dac ('give'). The shift marks two things: 1 ) the semantics of the verb clearly explicates the aim of the request, that is the sharing of a whole cigarette; 2) the aspect of the verb marks the authorship of sharing as Sebastian's initiative. The format is followed by już jaramy ('we smoke now') in the indicative mood, finalized with the terminative phrase $i$ koniec ('and that's it') and the particle no. This additional move serves to again prompt the action's immediateness and to encourage sharing by devaluing Piotr's idea of saving the last cigarette in the face of the general scarcity of this product.

The choice of an imperative in the second attempt clearly serves to induce Piotr that sharing the last cigarette with Sebastian is what the latter expects and considers as the best solution. This reveals the moral roots of the expectation that can be explicated as follows: 'When you have a scarce but sharable thing and others want you to share it, you do not keep it for yourself, but share it with them'. In other words, by selecting an imperative request in the face of resistance, Sebastian manifests that the act of sharing the whole cigarette with him is of higher moral (and rational) value than the requestee's ownership and autonomy. On these grounds the format appeals to the requestee's social responsibility and readiness for "being there" for the speaker (Zinken and Ogiermann 2013).

In a similar situation from Excerpt 12 (Norwegian), the requester's reaction to resistance is radically different. Anita comes out on the terrace where Rebekka is sitting and sunbathing and checks the availability of cigarettes with a prerequest (line 01). 
Excerpt 12: Norwegian (2.191)

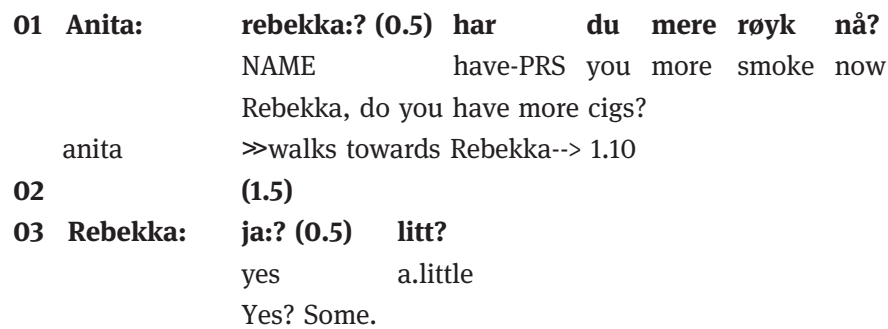

04 (.)

05 Anita: en? (.) to? (0.7) tre?

one two three

One? Two? Three?

$06 \quad$ (0.4)

07 Rebekka: $\uparrow$ nei> altså det spiller jo ikke noe rolle no so it-N play-PRS after.all NEG some role Well, it doesn't really matter

08 hvor mye jeg< $\uparrow$ ha:r, Where much I have-PRS how many I have,

$09 \quad$ (1.1)

10 Anita: e:m: $\uparrow e:$ fordi: $\uparrow e::^{\star}$ : nå er klokka halv fire ${ }^{\star}$, because now be.PRS clock-DEF half four Because it's half past three now,

anita

klokka fire får vi varene, clock-DEF four get-PRS we goods-DEF At four we're getting the goods,

(1.1)

(.)

15 Rebekka: vente til klokka fire?

wait-INF to clock-DEF four

Wait to four o'clock?

16

a(0.5) til du får varene?ø

to you get goods-DEF

Until you get the goods?

rebekka aturns her head, gazes at Anitaø 
17

18 Anita:

19

20

rebekka

21 Rebekka:

22

23 Anita:

rebekka $a(0.4) \quad a(0.8)$

aturns her head backp

ne:i men jeg har nettopp spist,

no but I have-PRS already eat-SUP

Well, I've just eaten,

og så skal jeg drikke kaffe og,

And so shall.PRS I drink-INF coffe and and I'm going to drink coffee and,

(1.0) $a($.

agazes at Anita-->

det æ'kke mitt problem $\dot{i}$

it-N be.PRS.NEG my-N problem

It's not my problem $i$

(.)

ne::i det æ'kkeø det?

no it-N be.PRS.NEG it-N

No, it isn't?

Anita's first turn is followed by a long pause and a positive answer (a go-ahead) that after half a second Rebekka complements with the indeterminate quantifier litt ('some'), already displaying resistance. This indicates that she does not, by default, treat the utterance as a request but rather as a literal question (a prerequest), as it is not responded to with direct compliance or refusal (see Rossi 2015; cf. Levinson 1983). Since the expected outcome is deferred, Anita takes the next step by launching an expansion of the pre-request that builds upon the quantifier from Rebekka's answer. By this move, she seeks to determine the amount of cigarettes Rebekka has, which allows her to assess the possibility of compliance (line 05). However, what Anita receives back in lines 07-08, is a blocking response (Schegloff 2007) that again delays the expected action. It is at this point that Anita decides to explicate her request by putting some more effort in getting Rebekka to share a cigarette. After a pause longer than a second, she initiates her turn with hesitation markers and an account (lines 10-11), marking the recognized dispreference of the upcoming request (Schegloff 2007). Then, after another long pause, she utters a Can I-interrogative with a modal auxiliary in the past tense (kunne 'could') and the elliptical form of the perfect infinitive (ha) fått ('to have recived'). The time displacement serves to mark the assumption about the granting of request as merely hypothetical and thus fully dependent on the requestee's willingness. In the face of Rebekka's resistance to share confirmed twice (lack of compliance after the pre-request and the blocking 
response in the expansion) Anita not only orients to this contingency, but also recognizes and acknowledges Rebekka's complete autonomy in this matter and appeals to her good will. This is validated in the following turns where Anita again accounts for her request and Rebekka eventually decides to share a cigarette with her.

Here we can notice a crucial difference between the two excerpts. As opposed to Sebastian from Excerpt 11, Anita acts within the interrogative matrix, modifying it internally into a less conventional format (cf. Urbanik 2017). This serves the same aim (to induce Rebekka to share) but follows a different path to obtaining it, based on expressing uncertainty and giving the requestee leeway. Thus, the moral grounds hidden behind this move could be explicated as follows: 'When somebody has a scarce but sharable thing and you want them to share it, you neither take compliance for granted nor manifest that you expect it'. Put differently, by selecting a marked interrogative request in the face of resistance, Anita marks that Rebekka's ownership and autonomy is of higher moral value than Anita's need. On these grounds the format reflects the requester's social responsibility for recognizing and acknowledging the requestee's freedom to decide whether to share or not.

In this section I have demonstrated that the distributional differences between the two data sets reflect deeper meanings in the ways people from the two cultures get others to share similar things in some similar situations. In the two sequential environments I have focused on, the Polish participants consistently selected imperatives while their Norwegian counterparts used transfer Can I-interrogatives, modifying them internally. As I have argued, the former treated sharing as the requestee's social obligation, while the latter framed it as the requester's domain of performance and responsibility for acknowledging the requestee's free choice.

\section{Discussion and conclusions}

The main contribution of this paper consists in demonstrating that the three syntactic designs of requests for sharing in Polish and Norwegian emerge from the interplay of three configurational conditions: 1) the requester's ownership claims to the object, 2) the requestee's control of the relevant object, and 3) the requester's orientation to contingencies (including other-located possession/ ownership). The first condition seems invariant. In none of the instances collected did the requester claim exclusive ownership of the object. ${ }^{10}$ The second condition (object control) affects the distribution of agency based on the

10 Otherwise, the request could unlikely express the aim of getting a thing shared. 
recognition whether at the moment of requesting the object is controlled by the requestee and needs to be transferred or whether, for one or another reason, it is not controlled and needs to be taken action on. The third condition (contingency) determines to what extent object possession becomes relevant for sharing due to recognized obstacles and thus to what extent the action of sharing is considered as troublesome for the requestee. Now, given the two variable conditions, the syntactic outcome seems to build upon their possible combinations, which may bear some predictive potential.

When the requestee was in control of the object and the requester did not orient to contingencies, the request for sharing the object through its transfer was framed as an imperative. When the requester decided to act on the object owned by the requestee whereas the latter did not (or could not) control it directly, the request for sharing was designed as a permission Can I-interrogative. When the requestee controlled the object but the requester nevertheless oriented to contingencies (including possession resulting from, e. g. the use of the object), the Can I-interrogative as a transfer request was selected. Figure 13 illustrates these relations.

Figure 13 also provides a possible explanation of how participants form and recognize such actions as requests for sharing goods. When the requester does not claim exclusive ownership to the object that is sharable, s/he creates a precondition for a potential request for sharing. Object control constitutes the

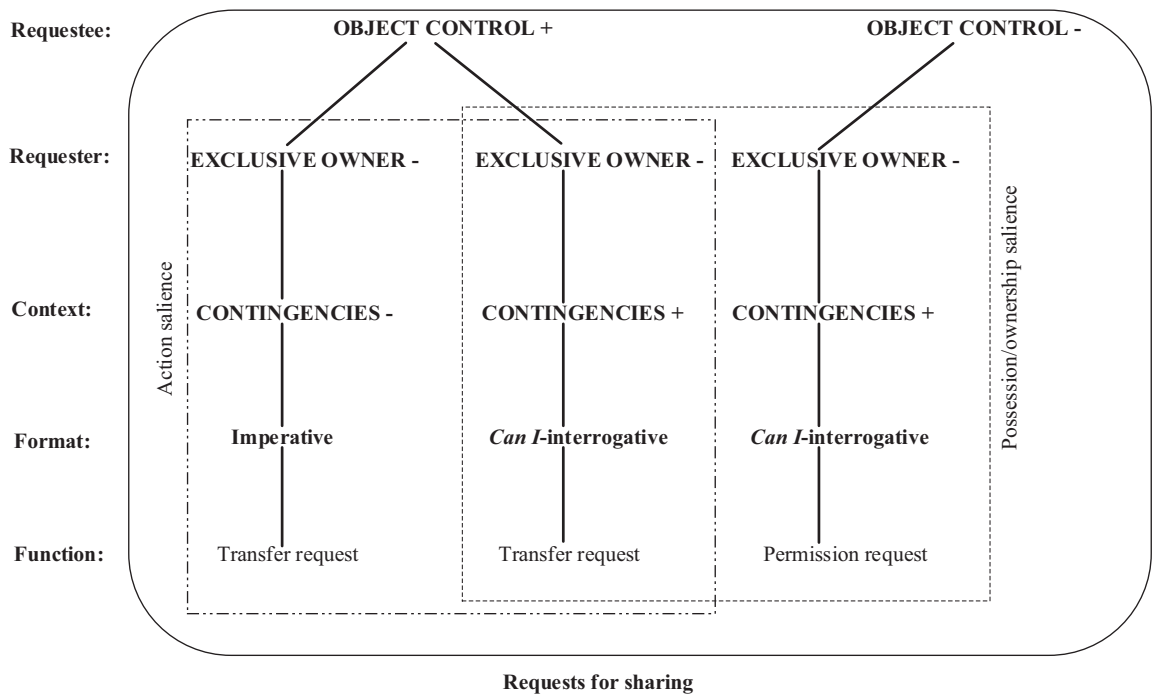

Figure 13: Formation/ascription of requests for sharing. 
prototypical division of interactional roles, meaning that the requestee controlling the relevant object is by default the animator of sharing, while the requester is the author of this event. When the object is not controlled and the requester acts on it, the interactional roles are different: The requester is both the animator and the author of sharing while the requestee remains coresponsible for sharing by granting permission. In the former case, the requester marks the relevance of the very action of sharing expected from the requestee (hence the imperative format), while in the latter case s/he emphasizes the relevance of ownership, as the action of sharing belongs to his/her domain of performance (hence the permission Can I-interrogative). However, the requester may also manipulate these stereotypical distributions of agency by marking the relevance of both the action of sharing and object possession. This makes up the borderline cases in which the requester, by asking for an object that is controlled by the requestee, orients to the premises that may hinder its sharing. In these situations, s/he selects a Can I-interrogative, although in the function of a transfer, not permission, request in which s/he takes the role of a passive animator of sharing.

In the description above the notions "object control" and "possession" are used separately, although they ontologically are synonymous. This is to emphasize that they operate at different levels of epistemic orientation. The spatiotemporal status of the object projects the type of action with respect to the object and the division of agency. This can be seen as what Hutchins (2005) calls a "material anchor for a conceptual blend". Thus, when an object is controlled by others (and not exclusively owned by the requester), it is blended with the concept of other-located possession or ownership and so forms the basis for sharing that may in turn be triggered by a request. In the dialogic situations in which requests emerge, artifacts and agents are not only salient points of reference, but entities that are incorporated into, reflected and exploited by the conventions of language use. The grammatical resources allow us to do this by manipulating the syntax, deixis, action verbs and object specification. As I have shown, based on prior or on-going events and/or hypothetical assumptions that make up real or potential obstacles, the requester may or may not orient to possession as a salient contingency. This is reflected in the grammatical design of the requests analyzed in this study. Imperatives do not mark recognition of contingencies and are used to invoke sharing when the requestee controls the object. Can I-interrogatives do mark recognition of contingencies but depending on the control status of an object they perform different actions: They either get people to share or ask for permission to get the thing shared. This difference in the use of interrogative formats is also revealed at the level of their semantic composition and sequential projection. Transfer Can I- 
interrogatives make use of different verbs than their permission counterparts (cf. the Norwegian $f a ̊$ 'receive' in the former vs. $t a$ 'take' in the latter). Furthermore, in the cases of preferred response, the latter normally project a verbal acceptance as the relevant next, while the former are often replied to with non-verbal compliance.

Rossano and Liebal (2014), who have analyzed the semiotics of requesting and offering among primates and human infants, show that as opposed to primates, infants make use of reaching gestures rather than begging gestures, although they recognize the latter's function. As we have seen in the previous section, the speakers most often employed reaching gestures despite the selected grammatical format (see Figures 1, 4, 6, 7, and 11). These embodied actions came right before or simultaneously with the verbal conduct and clearly revealed the requesters' presumptions about compliance, showing that sharing was often anticipated and treated as a natural display of prosocial behavior. Yet, although this positive projection of gestures is in line with the use of imperatives (Mondada 2017), it clashes with the use of Can I-interrogatives. Why then do participants mark that they expect compliance/acceptance while verbally expressing uncertainty in this matter? One possible answer is that their local orientations consist of at least two different but complementing each other trajectories. On the one hand, the requesters bodily mark their entitlement to expect sharing based on premises conducive to having this expectation. On the other hand, they verbally mark their recognition of real or potential obstacles that may undermine this entitlement and thus hinder compliance. My argument is therefore that in the case of apparent incongruence between the embodied action and the grammatical format, the latter serves to validate the meaning of the former. In other words, in the face of some obstacles oriented to by the requester, Can $I$-interrogatives seek the authorization for either the action taken on the object (permission interrogatives) or the manifested expectations regarding its transfer (transfer interrogatives). This demonstrates how speakers modulate their meanings at different levels of expression (gestural, prosodic etc.) and deliver them as one multidimensional package (or multimodal gestalt, cf. Mondada 2014; Holler and Levinson 2019). This also shows that such notions as entitlement and contingencies, although conventionally associated with certain grammatical formats (particularly imperatives and interrogatives, respectively), can be marked independently of grammar when conflicting premises come into play.

The above perspective on action formation/recognition fits in the recent developments within Conversation Analysis and Interactional Linguistics where grammatical designs are investigated in relation to the details of sequential and material environments. This study has confirmed previous observations 
on the differences between imperatives and interrogatives with respect to orientation to contingencies (Lindström 2005; Wootton 1997; Craven and Potter 2010; Rossi 2012; Zinken and Ogiermann 2013) and on the role of objects in action formation (Neville et al. 2014; Tuncer and Haddington 2019, see also Section 3). Yet, what the present paper has additionally proposed is an analysis narrowed to the type of requests that construct an event (sharing) to which participants orient. It has shown that this particular type of requests differs from other types (e. g. requests for passing or fetching an object) in that it operates on the combination of an object's control status and orientation (or lack of it) to ownership. It has also demonstrated that a group of requests labeled as Can Irequests (or permission requests) has in fact two pragmatically and grammatically different realization patterns (permission vs. transfer requests) that depend on the object's control status.

Now, how speakers assess the weight of contingencies that warrant their use of imperatives or Can I-interrogatives is a culture-specific matter. Thus, another contribution of this study is the identification of the moral roots of grammatical choices that lie at the heart of cross-cultural divergences. The paper has showed how a detailed, multimodal conversation-analytic examination of similar instances across languages can be used to identify cross-linguistic similarities and differences and how we can validly determine the parameters that co-compose distinctive social actions. Although all three syntactic conventions are found in Polish and Norwegian, the use of imperatives and transfer Can I-interrogatives differs across the languages. This is because the Norwegian participants more often seemed to mark their orientations to contingencies than their Polish counterparts did in similar contexts. A closer look at the sequential environments in which these divergences are found reveals that the latter made contingencies relevant only when they had good reasons to do this because they normally treated sharing as the requestees' social obligation. The Norwegian speakers, on the other hand, needed strong enough reasons to select imperatives, as they did not, by default, take the requestee's readiness to share for granted. This is in line with what has been observed in Polish and English (Zinken and Ogiermann 2013; Zinken 2016) as well as other languages (e.g. Bolden 2017 on Russian). The avoidance of the imposition of event animatorship on the requestee in the Norwegian culture is even reflected in the semantics of imperatives employed as requests for sharing. Contrary to Polish in which speakers frequently use the verb 'give' in the second person, in Norwegian this verb is used very rarely (no records in the data). Instead, speakers usually select the verb $f a ̊$ 'receive' that in its core meaning highlights receiving (i. e. the quasiagentive role of the requester as the beneficiary) and "hides" the real performer of sharing (i. e. masks the requestee's animatorship). This use of $f a ̊$ is the feature 
that bridges imperatives and Can I-interrogatives (cf. Section 5.4) at the level of both semantic composition and material configuration by conventionally manipulating the distribution of agency when an object is to be transferred. ${ }^{11}$ This demonstrates how our choice of a linguistic form in relation to spatio-temporal and material constellations results from and is consequential for the distribution of agency and accountability (Enfield 2017; Rossi and Zinken 2017).

The general difference between Polish and Norwegian is in line with what has been claimed about East-European and West-European cultures (Ogiermann 2009), the former being more imperatively and less interrogatively oriented than the latter. However, actual cultural differences result from local orientations in certain contextual configurations and seem to concern certain request types. The approach that examines these details is just developing within Conversation Analysis (see Zinken and Ogiermann 2013). It proposes a promising and more nuanced alternative to traditional cross-cultural comparisons, mainly based on discourse-completion tasks and intuition (Blum-Kulka et al. 1989; Wierzbicka 2003) rather than on observations of naturally occurring interactions. Table 2 summarizes the characteristics of the three formats analyzed in this study.

Due to the limitations of the present study (the character of the data and the collection size), the conclusions provided here need further confirmation from similar studies on various, also typologically divergent, languages. Yet, in general, what seems to make requests for sharing different from other requests, e. g. those for passing or fetching an object, is a particular holistic composition of grammatical conventions and embodied and material configurations. The selection of the request format that triggers sharing seems to happen through orientation to the control status of the object and its proximity as well as to the premises that make or do not make possession or ownership a salient contingency. Reasons for why speakers regularly assess these premises in one way or another and select certain request formats may have deeper moral and cultural roots that can be identified in the subtleties of their interactions with others and compared across cultures. Thus, statistical knowledge on their grammatical choices in the configurations described above and in various local and cultural contexts may carry substantial predictive value.

11 It may be that $f a ̊$-imperatives have appeared recently. According to Faarlund (1985), they were not common among adults a few generations ago. 
Table 2: General and language-specific features of the three formats as requests for sharing.

\begin{tabular}{|c|c|c|c|c|}
\hline $\begin{array}{l}\text { Request } \\
\text { type }\end{array}$ & Format & Common features & Features in Polish & $\begin{array}{l}\text { Features in } \\
\text { Norwegian }\end{array}$ \\
\hline Transfer & Imperative & $\begin{array}{ll}\text { - } & \text { Object con- } \\
\text { trolled by } \\
\text { recipient } \\
\text { - } & \text { No orientation } \\
& \text { to contingencies } \\
- & \text { Action salient } \\
- & \text { Positive embod- } \\
& \text { ied projection }\end{array}$ & $\begin{array}{l}\text { - } \quad \text { Frequent use } \\
\text { - Common use of } \\
\text { the verbs daj } \\
\text { 'give' and pokaż } \\
\text { 'show' }\end{array}$ & $\begin{array}{ll}\text { - } & \text { Infrequent use } \\
- & \text { Common use of } \\
& \text { the verb få 'get' }\end{array}$ \\
\hline Permission & $\begin{array}{l}\text { Can I- } \\
\text { interrogative }\end{array}$ & 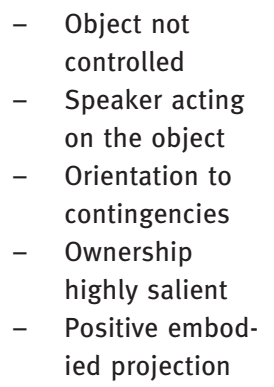 & $\begin{array}{l}\text { - Frequent lack of } \\
\text { V2 }\end{array}$ & $\begin{array}{l}\text { - Common use of } \\
\text { the verb ta 'take' } \\
\text { or låne 'borrow' } \\
\text { as V2 }\end{array}$ \\
\hline Transfer & $\begin{array}{l}\text { Can I- } \\
\text { interrogative }\end{array}$ & $\begin{array}{ll}\text { - } & \text { Object con- } \\
\text { trolled by } \\
\text { recipient } \\
\text { - } & \begin{array}{l}\text { Orientation to } \\
\text { contingencies }\end{array} \\
- & \text { Action salient } \\
- & \text { Possession/ } \\
\text { ownership } \\
\text { salient } \\
-\quad \text { Positive embod- } \\
\text { ied projection }\end{array}$ & - Infrequent use & $\begin{array}{ll}\text { - } & \text { Frequent use } \\
\text { - } & \text { The verb få } \\
& \text { ('get') as V2 }\end{array}$ \\
\hline
\end{tabular}

Acknowledgements: I am grateful to Jakob Steensig and Jan Svennevig for their invaluable comments on the early drafts of this article. My thanks also go to Janne Bondi Johannessen for dispelling any doubts concerning the Norwegian syntax. Last but not least, I thank the two anonymous reviewers for getting me to make this article better. Any mistakes are mine. 


\section{References}

Blum-Kulka, Shoshana, Juliane House \& Gabriele Kasper. 1989. Cross-cultural pragmatics: Requests and apologies. Norwood: Ablex Publishing Corporation.

Bolden, Galina. 2017. Requests for here-and-now actions in Russian conversation. In MarjaLeena Sorjonen, Liisa Raevaara \& Elizabeth Couper-Kuhlen (eds.), Imperative turns at talk: The design of directives in action, 175-211. Amsterdam \& Philadelphia: John Benjamins Publishing Company.

Brownell, Celia A., Stephanie S. lesue, Sara R. Nichols \& Margarita Svetlova. 2013. Mine or yours? Development of sharing in toddlers in relation to ownership understanding. Child Development 84(3). 906-920.

Brownell, Celia A., Margarita Svetlova \& Sara Nichols. 2009. To share or not to share: When do toddlers respond to mother's needs? Infancy 14(1). 117-130.

Bruner, Jerome, Carolyn Roy \& Nancy Ratner. 1982. The beginnings of request. In Keith E. Nelson (ed.), Children's language: Volume 3, 91-138. Hillsdale: Lawrence Erlbaum Associates.

Couper-Kuhlen, Elizabeth \& Margret Selting. 2018. Interactional linguistics: Studying language in social interaction. Cambridge: Cambridge University Press.

Craven, Alexandra \& Jonathan Potter. 2010. Directives: Entitlement and contingency in action. Discourse Studies 12(4). 419-442.

Dixon, Sally. 2015. Gimme! Gimme! Gimme!: Objects requests, ownership and entitlement in a children's play session. Journal of Pragmatics 82. 39-51.

Drew, Paul \& Elizabeth Couper-Kuhlen (eds.). 2014a. Requesting in social interaction. Amsterdam \& Philadelphia: John Benjamins Publishing Company.

Drew, Paul \& Elizabeth Couper-Kuhlen. 2014b. Requesting - from speech act to recruitment. In Paul Drew \& Elizabeth Couper-Kuhlen (eds.), Requesting in social interaction, 1-34. Amsterdam \& Philadelphia: John Benjamins Publishing Company.

Enfield, Nick J. 2013. Relationship thinking: Agency, enchrony, and human sociality. Oxford: Oxford University Press.

Enfield, Nick J. 2017. Distribution of agency. In Nick J. Enfield \& Paul Kockelman (eds.), Distributed agency, 9-14. Oxford: Oxford University Press.

Ervin-Tripp, Susan \& David Gordon. 1986. The development of requests. In Richard L. Schiefelbusch (ed.), Communicative competence: Acquisition and intervention, 61-95. Beverly Hills: College Hills Press.

Etelämäki, Marja \& Elizabeth Couper-Kuhlen. 2017. In the face of resistance: A Finnish practice for insisting on imperatively formatted directives. In Marja-Leena Sorjonen, Liisa Raevaara \& Elizabeth Couper-Kuhlen (eds.), Imperative turns at talk: The design of directives in action, 215-240. Amsterdam \& Philadelphia: John Benjamins Publishing Company.

Faarlund, Jan Terje. 1985. Imperative and control. First person imperatives in Norwegian. Nordic Journal of Linguistics 8. 149-160.

Fehr, Ernst, Helen Bernhard \& Bettina Rockenbach. 2008. Egalitarianism in young children. Nature 454. 1079-1084.

Fox, Barbara \& Trine Heinemann. 2016. Rethinking format: An examination of requests. Language in Society 45(4). 499-531.

Fox, Barbara \& Trine Heinemann. 2017. Issues in action formation: Requests and the problem with x. Open Linguistics 3. 31-64.

Goffman, Erving. 1979. Footing. Semiotica 25(1-2). 1-30. 
Gordon, David \& Susan Ervin-Tripp. 1984. The structure of children's requests. In Richard L. Schiefelbusch \& Joanne Pickar (eds.), The acquisition of communicative competence, 295-322. Baltimore: University Park Press.

Gurven, Michael. 2004. To give and to give not: The behavioral ecology of human food transfers. Behavioral and Brain Sciences 27. 543-583.

Gurven, Michael \& Adrian V. Jaeggi. 2015. Food sharing. In Robert Scott \& Stephan Kosslyn (eds.), Emerging trends in the social and behavioral sciences: An interdisciplinary, searchable, and linkable resource, John Willey \& Sons. https://doi.org/10.1002/ 9781118900772.etrds0133 (accessed 28 July 2019).).

Hay, Dale F. 1979. Cooperative interactions and sharing between very young children and their parents. Developmental Psychology 15(6). 647-653.

Hay, Dale F. \& Kaye V. Cook. 2007. The transformation of prosocial behavior from infancy to childhood. In Celia A. Brownell \& Claire B. Kopp (eds.), Socioemotional development in the toddler years: Transitions \& transformations, 100-131. New York: Guilford Press.

Hepburn, Alexa \& Galina B. Bolden. 2013. The conversation analytic approach to transcription. In Jack Sidnell \& Tanya Stivers (eds.), The handbook of conversation analysis, 57-76. Chichester: Wiley-Blackwell.

Holler, Judith \& Stephen C. Levinson. 2019. Multimodal language processing in human communication. Trends in Cognitive Sciences 23(8). 639-652.

House, Bailey R., Joan B. Silk, Joseph Henrich, H. Clark Barrett, Brooke A. Scelza, Adam H. Boyette, Barry S. Hewlett, Richard McElreath \& Stephen Laurence. 2013. Ontogeny of prosocial behavior across diverse societies. PNAS 110(36). 14586-14591.

Hutchins, Edwin. 2005. Material anchors for conceptual blends. Journal of Pragmatics 37. 1555-1577.

Johannessen, Janne Bondi. 2016. Prescriptive infinitives in the modern North Germanic languages: An ancient phenomenon in child-directed speech. Nordic Journal of Linguistics 39(3). 231-276.

Kaplan, Hillard \& Kim Hill. 1985. Food sharing among ache foragers: Test of explanatory hypotheses. Current Anthropology 26(2). 223-239.

Levinson, Stephen C. 1983. Pragmatics. Cambridge: Cambridge University Press.

Levinson, Stephen C. 2013. Action Formation and Ascription. In Jack Sindell \& Tanya Stivers (eds.), The Handbook of Conversation Analysis, 103-130. Chichester: Wiley-Blackwell.

Lindström, Anna. 2005. Language as social action: A study of how senior citizens request assistance with practical tasks in the Swedish home help service. In Auli Hakulinen \& Margret Selting (eds.), Syntax and lexis in conversation: Studies on the use of linguistic resources in talk-in-interaction, 209-230. Amsterdam/Philadelphia: John Benjamins Publishing Company.

Mondada, Lorenza. 2014. The local constitution of multimodal resources for social interaction. Journal of Pragmatics 65. 137-156.

Mondada, Lorenza. 2016. Conventions for multimodal transcription. https://franzoesistik. philhist.unibas.ch/fileadmin/user_upload/franzoesistik/mondada_multimodal_conven tions.pdf (accessed 07 April 2019).

Mondada, Lorenza. 2017. Precision timing and timed embeddedness of imperatives in embodied courses of action. Examples of French. In Marja-Leena Sorjonen, Liisa Raevaara \& Elizabeth Couper-Kuhlen (eds.), Imperative turns at talk: The design of directives in action, 65-101. Amsterdam/Philadelphia: John Benjamins Publishing Company. 
Moravcsik, Julius M. 2004. The ties that bind. Budapest \& New York: Central European University Press.

Neville, Maurice, Pentti Haddington, Trine Heinemann \& Mirka Rauniomaa. 2014. Interacting with objects: Language, materiality, and social activity. Amsterdam/Philadelphia: Jon Benjamins Publishing Company.

Ogiermann, Eva. 2009. Politeness and in-directness across cultures: A comparison of English, German, Polish and Russian requests. Journal of Politeness Research 5. 189-216.

Ogiermann, Eva. 2015. Direct off-record requests? - 'Hinting' in family interactions. Journal of Pragmatics 86. 31-35.

Rossano, Federico \& Katja Liebal. 2014. "Requests" and "offers" in orangutans and human infants. In Paul Drew \& Elizabeth Couper-Kuhlen (eds.), Requesting in social interaction, 335-363. Amsterdam \& Philadelphia: John Benjamins Publishing Company.

Rossi, Giovanni. 2012. Bilateral and unilateral requests: The use of imperatives and $\mathrm{mi} X$ ? Interrogatives in Italian. Discourse Processes 49(5). 426-458.

Rossi, Giovanni. 2015. Responding to pre-requests: The organization of hai x 'do you have' sequences in Italian. Journal of Pragmatics 82. 5-22.

Rossi, Giovanni \& Jörg Zinken. 2017. Social agency and grammar. In Nick J. Enfield \& Paul Kockelman (eds.), Distributed agency, 79-86. Oxford: Oxford University Press.

Schegloff, Emanuel A. 2007. Sequence organization in interaction. A primer in conversation analysis. Cambridge: Cambridge University Press.

Schmidt, Marco F. H. \& Jessica A. Sommerville. 2011. Fairness expectations and altruistic sharing in 15-month-old human infants. PLoS ONE 6(10). e23223. https://doi.org/10.1371/ journal.pone.0023223 (accessed 28 July 2019).

Searle, John. 1969. Speech acts: An essay in the philosophy of language. London: Cambridge University Press.

Sidnell, Jack \& Nick J. Enfield. 2012. Language diversity and social action: A third locus of linguistic relativity. Current Anthropology 53(3). 302-333.

Silk, Joan B. \& Bailey R. House. 2016. The evolution of altruistic social preferences in human groups. Philosophical Transactions of the Royal Society B 371. 20150097. https://royalso cietypublishing.org/doi/10.1098/rstb.2015.0097 (accessed 28 July 2019).

Sorjonen, Marja-Leena, Liisa Raevaara \& Elizabeth Couper-Kuhlen. 2017. Imperative turns at talk: The design of directives in action. Amsterdam \& Philadelphia: John Benjamins Publishing Company.

Takada, Akira \& Tomoko Endo. 2015. Object transfer in request-accept sequence in Japanese caregiver-child interactions. Journal of Pragmatics 83. 52-66.

Terasaki, Alene Kiku. 2004. Pre-announcement sequences in conversation. In Gene H. Lerner (ed.), Conversation analysis: Studies from the first generation, 171-223. Amsterdam \& Philadelphia: John Benjamins Publishing Company.

Tomasello, Michael. 2009. Why we cooperate. Cambridge \& London: A Boston Review Book \& The MIT Press.

Tuncer, Sylvaine \& Pentti Haddington. 2019. Object transfers: An embodied resource to progress joint activities and build relative agency. Language in Society 1-27. doi:10.1017/ S004740451900071X.

Urbanik, Pawet. 2017. Requests in Polish and Norwegian informal conversation: A comparative study of grammatical and pragmatic patterns. Unpublished PhD thesis. Oslo: University od Oslo, Department of Linguistics and Scandinavian Studies. 
Urbanik, Pawet \& Jan Svennevig. 2019. Managing contingencies in requests: The role of negation in Norwegian interrogative directives. Journal of Pragmatics 139. 109-125.

Warneken, Felix \& Michael Tomasello. 2006. Altruistic helping in human infants and young chimpanzees. Science 311(5756). 1301-1303.

Warneken, Felix \& Michael Tomasello. 2009a. Varieties of altruism in children chimpanzees. Trends in Cognitive Sciences 13(9). 397-402.

Warneken, Felix \& Michael Tomasello. 2009b. The roots of human altruism. British Journal of Psychology 100. 455-471.

Wierzbicka, Anna. 2003. Cross-cultural pragmatics: The semantics of human interaction. Berlin/ New York: Mouton de Gruyter.

Wootton, Anthony. 1981. Two request forms of four year olds. Journal of Pragmatics 5. 511-523.

Wootton, Anthony. 1997. Interaction and the Development of Mind. Cambridge: Cambridge University Press.

Yamamoto, Shinya \& Masayuki Tanaka. 2009. How did altruism and reciprocity evolve in humans? Perspectives from experiments on chimpanzees (Pan troglodytes). Interaction Studies 20(2). 150-182.

Zinken, Jörg. 2015. Contingent control over shared goods. 'Can I have x' requests in British English informal interaction. Journal of Pragmatics 82. 23-38.

Zinken, Jörg. 2016. Requesting responsibility: The morality of grammar in Polish and English family interaction. Oxford: Oxford University Press.

Zinken, Jörg \& Eva Ogiermann. 2013. Responsibility and action: Invariants and diversity in requests for objects in British English and polish interaction. Research on Language and Social Interaction 46(3). 256-276.

\section{Bionote}

\section{Pawet Urbanik}

Paweł Urbanik is a Postdoctoral Researcher at Center for Multilingualism in Society across the Lifespan, University of Oslo. His areas of research are Interactional Linguistics, Forensic Linguistics, Conversation Analysis, Pragmatics, and Polish and Norwegian grammar.

\section{Appendix 1}

CA transcription symbols

(.) micropause less than 0.2 seconds

(0.3) pause in seconds and tenths of a second

[ beginning of overlapping talk

] end of overlapping talk

$=\quad$ latched talk between the speakers

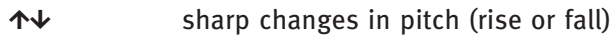

? $\quad$ strongly rising intonation 


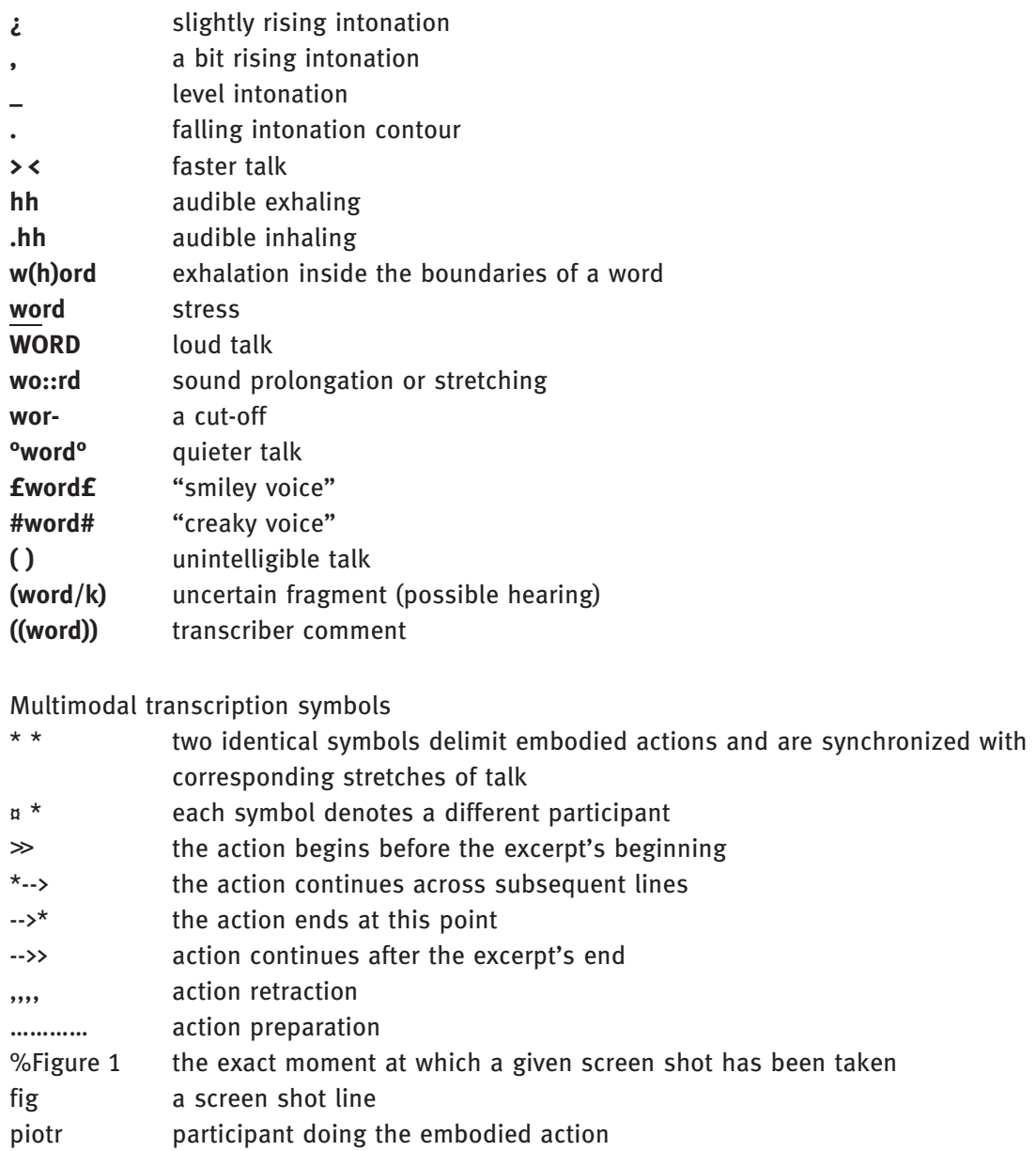

\section{Appendix 2}

Glossing symbols

$\begin{array}{ll}\text { 1, 2, } 3 & \text { person } \\ \text { ACC } & \text { accusative } \\ \text { ADJ } & \text { adjective } \\ \text { ADV } & \text { adverb } \\ \text { ART } & \text { article } \\ \text { DAT } & \text { dative } \\ \text { DEF } & \text { definite } \\ \text { DIM } & \text { diminutive }\end{array}$




$\begin{array}{ll}\text { FUT } & \text { future tense } \\ \text { GEN } & \text { genitive } \\ \text { IMP } & \text { imperative } \\ \text { INF } & \text { infinitive } \\ \text { INTJ } & \text { interjection } \\ \text { IPFV } & \text { imperfective aspect } \\ \text { NAME } & \text { proper noun } \\ \text { NEG } & \text { negation } \\ \text { PFV } & \text { perfective aspect } \\ \text { PL } & \text { plural } \\ \text { PRS } & \text { present tense } \\ \text { PRT } & \text { particle } \\ \text { PST } & \text { past tense } \\ \text { SG } & \text { singular } \\ \text { SUP } & \text { supine } \\ \text { VOC } & \text { vocative }\end{array}$

